\title{
Über die Selbststerilität von Veronica syriaca.
}

\author{
Von Ernst Lehmann, Tübingen.
}

(Eingegangen 3. September 1918.)

\section{Inhalt.}

A. Einleitung

1. Isolation . . . . . . . . . . . . . . . . . . . . . . . 4

2. Bestäubang . . . . . . . . . . . . . . . . . . . . . . 4

3. Markierung der Blüten . . . . . . . . . . . . . . . . . . 7

C. Die ausgeführten Bestäubungen . . . . . . . . . . . . . . . . .7

1. Feststellung einer Gruppenbildung der $F_{1}$-Individuen durch gegenseitige künstliche Bestäubung

a) Die Gruppenbildung innerhalb 32 beliebig herangezogener Pflanzen $\operatorname{der} \mathrm{F}_{1}$. . . . . . . . . . . . . . . . . . . . . . . 8

b) Die Gruppenbildung erwiesen an möglichst zahlreichen $\mathbf{F}_{\mathbf{1}}$-Pflanzen . 21

2. Feststellung der Gruppenbildung durch Isolation der vier Gruppen an weit voneinander entfernten Plätzen im Freien . . . . . . . . . . 32

3. Die Selbststerilität . . . . . . . . . . . . . . . . . . . . 37

D. Mendelistische Erklärungsversuche . . . . . . . . . . . . . . . . 38

E. Ergcbnisse . . . . . . . . . . . . . . . . . . . . . . . . 46

F. Literatur . . . . . . . . . . . . . . . . . . . . 46

\section{A. Einleitung.}

Durch die in den letzten Jahren von verschiedenen Seiten und unter verschiedenen Gesichtspunkten unternommenen Untersuchungen an selbststerilen Pflanzen, auf welche ich weiter unten zurückkommen werde, hat sich gezeigt, daß die Selbststerilität sicher nicht einheitlicher Natur ist. Es sind im Gegenteil wohl zweifellos mannigfaltige Ursachen fïr das Zustandekommen derselben verantwortlich zu machen. Die his- 
herigen Untersuchungen haben uns aber noch in kaum einem Falle nach allen Richtungen hin befriedigende Aufschlüsse erteilt. Es erschien mir deshalb lohnend, ein neues Beispiel einer selbststerilen Pflanze möglichst eingehend und unter verschiedenen Gesichtspunkten zu untersuchen. Als ich daher in Veronica syriaca eine bis dahin als selbststeril noch unbekannte Pflanze auffand, entschloß ich mich, die Selbststerilität dieser Veronica-Art näher zu untersuchen. Ich habe über die anfänglichen Versuche schon in vorläufiger Form berichtet (1917). Es zeigte sich damals, daB die untersuchten Pflanzen stets vollkommen selbststeril waren. Selbstfertile Pflanzen konnte ich nicht auffinden. Dagegen ergab sich, als ich einzelne Pflanzen paarweis an verschiedenen, weit voneinander entfernten Stellen Ulms zur freien Kreuzung aufstellte, daß nicht alle untereinander fertil waren, sondern, daß, ganz ähnlich wie das de Vries, Correns und Sirks für ihre Versuchspflanzen fanden, die einen miteinander fruchtbar waren, während die anderen völlig steril untereinander blieben.

Nach diesen Vorversuchen wendete ich mich in den Sommern 1917 und 18 zur systematischen Untersuchung der Frage. Als Ausgangsmaterial benutzte ich eine blaublühende und eine rosablühende Pflanze von $V$. syriaca, welche aus früher von Haage u. Schmidt erhaltenen Samen erzogen wurden. Die beiden Pflanzen waren gemeinsam in einem Garten bei dem Fort Albeck bei Ulm, mitten in Feldern, fernab von jedem Ziergarten untergebracht, wo sie von Herrn Samenhändler Banzenmacher, dem ich hierfür zu herzlichem Danke verpflichtet bin, versorgt wurden. Eine Verunreinigung durch Pollen anderer Pflanzen von $V$. syriaca war dort ausgeschlossen, da V. syriaca bei uns nicht wild vorkommt und auch in Gärten weit und breit nicht kultiviert wird. In der für Ulm und einen großen Teil Württembergs maßgebenden Samenhandlung von Banzenmacher war die Pflanze völlig unbekannt, auch war ihr Anbau Herrn Hofgartendirektor Berger in Stuttgart sonst nirgends in Lande begegnet. Ich erzielte eine gute Samenernte. Die Samen beider gemeinsam isolierten Pflanzen wurden im Februar 1918 in einem Topf mit sterilisierter Erde im botanischen Garten Tübingen ausgesät. Die aufgegangenen Sämlinge, 198 an der Zahl, wurden in geeigneter Größe von mir selhst pikiert, jedes Pflänzchen in einen eigenen kleinen Topf. Hier entwickelten sich die Pflanzen ausnahmslos kräftig und schön zu iebhaft dunkelgrünen Individuen. Nach abermaliger Verpflanzung in größere Töpfe kamen sie in offene Kästen und begannen hier Wnde April zu blühen. Sie blühten, wie zu erwarten war, sämtlich blau. 
Ich stellte mir nun zunächst zwei Aufgaben:

1. Es sollten möglichst viele Kombinationen hergestellt werden zwischen den Individuen dieser meiner $\mathrm{F}_{1}$ ähnlich wie es Correns bei seinen Cardaminepflanzen zwischen Elter- und Kinderpflanzen gemacht hatte.

2. Es sollte untersucht werden, ob wirklich alle die zu prüfenden Pflanzen selbststeril waren.

Eine Bestäubung der $\mathbf{F}_{1}$-Pflanzen mit ihren Eltern von 1917 war nicht möglich, da die Elternpflanzen einjährig sind und durch den vorigen Winter nicht überwintert werden konnten. Auch die Bestäubung der $\mathrm{F}_{1}$-Pflanzen mit einer $\mathrm{F}_{2}$ erwies sich vorläufig noch nicht als ausführbar, da die einjährigen Pflanzen früher abgeblüht waren, ehe die eine Samenruhe durchmachenden Samen wieder auskeimten. Ich hoffe aber dennoch durch geeignete Maßnahmen Eltern und Kindergeneration einander so nähern zu kömnen, daß sich die Bestäubung beider untereinander wird ermöglichen lassen. Die im folgenden mitgeteilten Versuchsergebnisse beziehen sich aber zunächst nur auf die beschriebene $\mathrm{F}_{1}$-Generation.

Daß es nicht möglich war, alle Kombinationen zwischen meinen 198 Versuchspflanzen auszuführen, ist ohne weiteres klar (vergl, dazu Correns, Sirks usw.). Wie ich vorging, um dennoch möglichst viele Pflanzen auf ihr Verhalten untereinander zu prüfen, werde ich später darlegen.

\section{B. Methodik.}

Auf die Schwierigkeiten, so zahlreiche Kreuzungen während einer immerhin beschränkten Blütezeit mit der nötigen Zuverlässigkeit und Zweifelsfreiheit herzustellen, hat Correns bei seinen Untersuchungen an Cardamine pratensis schon hingewiesen. Aus seinen Mitteilungen ersieht man, wie aufeinanderfolgende Bestäubungen zwischen denselben Pflanzen oftmals recht verschiedenartige Ergebnisse erbrachten. Die Kritik hat hierbei mehrfach eingesetzt (vergl. Compton, East, Sirks). Und Correns selbst bleibt sich hie und da im Zweifel, worauf unerwartete Bestäubungsergebnisse zurückzuführen sind, ob auf in der Pflanze liegende Gesetzmäßigkeiten oder auf die oder jene Fehlerquelle bei den Kreuzungen. Da auch ich bei meinen Veronicis mit all diesen Fehlerquellen zu rechnen hatte, so wird es notwendig, auf diese wie auf meine Methodik überhaupt hier etwas näher einzugehen. Wir werden allerdings sehen, daß sich die Fehlerquellen bei meiner Versuchspflanze sehr einschränken ließen. 


\section{Isolation.}

Correns isolierte seine Pflanzen derart, daß die 60 von ihm benutzten Versuchspflanzen in einem geräumigen vierteiligen Gazehaus untergebracht wurden. Durch die Isolation einer so großen Anzahl von Pflanzen in vier Fächern eines Gazehauses sind nun naturgemäß ziemlich zahlreiche Fehlerquellen gegeben. Correns selbst führt als Ursachen unbeabsichtigter Bestäubungen die Manipulationen an, welche beim Herausnehmen der Pflanzen behufs Bestäubens und beim Wiederhineinstellen in die Abteilungen des Gazehauses vorgenommen werden mußten. Natürlich werden auch gelegentlich beim Gießen usw. eingedrungene Insekten $z$ wischen den zahlreichen gemeinsam isolierten Individuen mancherlei Kreuzbestäubungen ausführen können. Bei meinen Versuchspflanzen mit den außerordentlich zahlreichen Blüten, den weit aus den Blüten vorragenden Antheren mit dem sehr lose sitzenden Pollen war nun eine gemeinsame Isolierung einer größeren Anzahl von Versuchspflanzen, welche ich ursprüngllich auch beabsichtigte, gänzlich ausgeschlossen. Wie mir versuchsweis gemeinsame Isolierung von je vier Pflanzen zeigte, kamen dabei nicht wenig unbeabsichtigte Bestäubungen zustande. Ich entschloß mich deshalb gleich zu Beginn meiner Untersuchungen dazu, mir für jede meiner Versuchspflanzen ein besonderes Isolationsbehältnis herstellen $\mathrm{zu}$ lassen. Ich ließ deshalb 50 Isolationsschränkchen mit Klapptüren machen was ausreichte, da immer nur eine beschränkte Anzahl aller Versuchspflanzen zugleich in Arbeit genommen werden konnte und somit gleichzeitig isoliert werden mußte. Die Bespannung geschah teilweise mit Gaze, zum anderen Teil mit weißem oder gelbem Fahnentuch. Alle Kästchen waren sehr sorgfältig mit Vorlegleisten gedichtet und wurden dauernd unter Revision gehalten, so daß Undichtigkeiten nicht vorkamen. Die auf Gestellen untergebrachten Isolationsbehältnisse zeigt Fig. 1. An jedes Behältnis w'urde immer die Nummer der jeweiligen Versuchspflanze angeschricben, so daß hintereinander stets nur die gleiche Versuchspflanze eingebracht wurde, da etwa abgestreifter Pollen Unregelmäßigkeiten hätte nach sich ziehen können. So war also für vollständige Isolation der Versuchspflanzen aufs beste gesorgt.

\section{Bestäubung.}

Zur Bestäubung wurden anfangs manchmal mehrere, später aber stets nnr zwei Pflanzen auf einmal aus den Kästen entnommen. Um in der zul Gebote stehenden Zeit die nötigen Bestäubungen vornehmen zu können und durch das danernde aus den Kästen Holen und Wieder- 
hineintragen keine unnötige Zeit zu verlieren, ließ ich mir die Pflanzen der Reihe nach von meiner Helferin zutragen und konnte so ohne größere Unterbrechung wochenlang jeden Nachmittag von $1 / 23-8 \mathrm{Uhr}$ bestäuben. Da mich das Wetter im Frühjahr 1918 durch langandauernde Trockenheit sehr stark begünstigte, konnte ich sehr zahlreiche Bestäubungen ausführen.

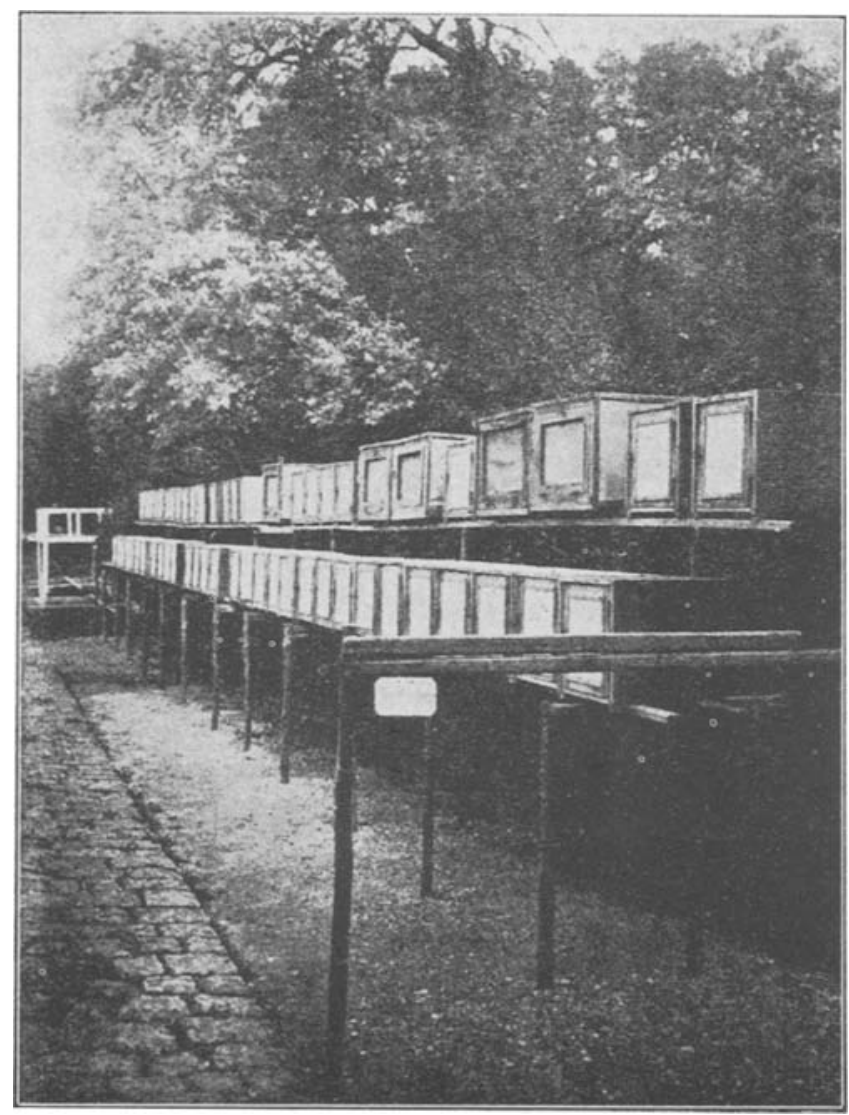

Fig. 1.

Zwecks Bestäubung wurde zunächst die Blumenkrone mit den beiden Staubblättern entfernt. Dies konnte ebensogut geschehen, wenn sich die Antheren schon geöffnet hatten, als wenn sie noch geschlossen waren; denn der Pollen der eigenen Blüte hatte, wie wir später noch sehen werden, niemals eine Wirkung auf die eigene Narbe. Eine gelegentliche Bestäubung der eigenen Narbe mit eigenem Pollen schadete aber dem Versuchsergebnis, 
wie häufig nachgeprüft wurde, durchaus nichts; dennoch wurde eine solche Bestäubung möglichst verhindert. Der Versuchspollen wurde dadurch auf die Narbe gebracht, daß eine geöffnete Anthere mit reichlichem Pollen mit der Pinzette auf der Narbe verrieben wurde. Das Zustandekommen der Bestäubung ließ sich immer dadurch gut erkemuen, daß der gelbgefärbte Pollen die weiße Narbe lebhaft färbte. In zweifelhaften Fällen wurde mit der Lupe nachkontrolliert, was aber nur selten notwendig wurde. Bei dieser Form der Bestäubung blieben relativ recht selten Bestäubungen aus, wo sie zu erwarten gewesen wären. Daß dies aber doch vorkam, das hat zunächst eine Reihe äußerer Gründe. Einmal mußten manchmal, um die nötigen Bestäubungen vollzählig zu erzielen, auch Pflanzen zu Zeiten mit herangezogen werden, wo sie nicht mehr in durchaus guter Beschaffenheit waren. Das macht sich leicht auch in etwas mangelhafter Ausbildung des Pollens bemerkbar. Zudem hatten an Regentagen im Hause wie am Abend sehr heißer Tage im Freien angestellte Bestäubungen manchmal nicht den vollen Erfolg. Es mag auch vorgekommen sein, daß noch nicht oder nicht mebr voll emplängnisfähige Narben bestäubt wurden, wenngleich das wohl eine besondere Ausnahme sein dürfte, da die Narben schon vor Öffnung der l3lüten und zumeist auch noch einige Zeit nach Abfallen derselben empfängnisfähig' zu sein pflegen. Wie weit dann auch noch tiefer liegende Gründe für ein gelegentliches Versagen von Bestäubungen verantwortlich zu machen sind, wird später erörtert werden. Es genïge hier hervorzuheben, daß das Versageu von Bestäubungen in Fällen, wo Erfolg zu erwarten gewesen wäre, durch öfters wiederholte, sicher eillwandfreie Bestäubungen fast ausnahmslos auf äußere Bedingungen zurückgeführt werden konnte.

Wie Versager kamen gelegentlich auch erfolgreiche Bestäubungen vor, wo sie nicht zu erwarten gewesen wären. Auch hierfür sind natürlich eine Reihe äuBerer, zufälliger Gründe verantwortlich zu machen, wie ja auch Correns bei seinen Cardamine-Versuchen ansführte. Die + Abweichungen stellten sich aber sehr viel seltener ein, als die - - Abweichungen. Nur ganz zu Anfang, als mehrere Pflanzen in einem Isolierkasten zur Isolation kamen, kamen sie etwas häufiger vor. Das ist selır verständlich, da eben hier eine gelegentliche Kreuzbestäubung durch Berühren oder eingedrungene Insekten sicher nicht völlig auszuschließen war. Natürlich sind auch andere äußere Möglichkeiten für das Zustandekommen unerwarteter Bestäubungen denkbar. Wenn eine Pflanze hintereinander mit Pollen verschiedener anderer Pflanzen bestäubt wird, so kaun die vielleicht etwas pollenbestäubte Pinzette eine Narbe berühren usw. Eine 
zwischengeschaltete Alkoholreinigung wurde indessen zwar zeitweis ausgeführt, konnte aber dann als überflüssig wieder weggelassen werden. Sodann ist natürlich zu berücksichtigen, daß bei Ausführung so zahlreicher Bestäubungen auch ganz einfache Versehen mit unterlaufen können, so sehr man sich bemüht, dieselben völlig auszuschließen. Die Zahl der unerwarteten erfolgreichen Bestäubungen ist aber, wie aus den Tabellen sich ergeben wird, sehr klein, zumal wie wir erfahren werden, gerade für +-Abweichungen tiefer liegende Ursachen vorhanden sein können, auf deren Betrachtung später eingegangen werden wird.

\section{Markierung der Blüten.}

Die bestäubten Blüten wurden mit einem an einem Fädchen befestigten Zettel, welcher mit der laufenden Nummer der bestäubten Blüte jeder Pflanze bezeichnet war, markiert und die Nummern für jede Pflanze getrennt mit dem zugehörigen Vermerk in das Tagebuch eingetragen.

\section{Die ausgeführten Bestäubungen.}

\section{Feststellung einer Gruppenbildung der $\mathbf{F}_{1}$-Individuen durch gegenseitige künstliche Bestäubung.}

Ich benutzte zunächst ganz wahllos die gerade zuerst erblübten Pflanzen, isolierte sie und bestäubte sie gegenseitig. Schon sehr bald stellte sich heraus, daß auch unter meinen $\mathrm{F}_{1}$-Pflanzen die Bestäubung zwischen manchen Individuen zur Ausbildung fruchtbarer Kapseln führte, während bei Bestäubung anderer Pflanzen keine fruchtbaren Kapseln erzielt wurden, wie ich das auch 1917 schon gelegentlich beobachtete. Nach einer größeren Reihe von Bestäubungen erwies sich weiterhin die Zahl der Pflanzen, welche untereinander fruchtbar waren, erheblich größer als die Zahl derer, welche miteinander steril waren. Auch eine weitere Tatsache konnte nicht lange übersehen werden, daß nämlich das Gelingen oder Mißlingen einer Bestäubung zwischen zwei Pflanzen stets reziprok war. Gelang die Bestäubung nach der einen Richtung, so führte sie stets auch nach der auderen Richtung zu positivem Resultat und umgekehrt. All dies wird durch die weiter unten angeführten Tabellen belegt werden. Unerwartete Ergebnisse störten, wie ebenfalls aus den Tabellen hervorgehen wird, das Gesamtresultat durchaus nicht in nennenswerter Weise, da ich solche unerwartete Ergebnisse mit wenigen, am Materialverfall scheiternden Ausnahmen stets durch zahlreiche Nachbestäubungen überprüfte. 
a) Die Gruppenbildung innerhalb 32 beliebig herangezogener Pflanzen der $\mathrm{F}_{1}$.

Als nun die Zahl meiner Kreuzungen auf immer zahlreichere Individuen ausgedehnt wurde, trat mit steigender Deutlichkeit eine neue Tatsache hervor. Unter den $\mathrm{F}_{1}$-Pflanzen meiner Kreuzung von 1917 fanden sich vier durch ihre Bestäubungsverhältnisse scharf geschiedene Gruppen von Pflanzen. Die Angehörigen jeder dieser vier Gruppen zeigten sich untereinander vollkommen steril, aber mit jedem einzelnen Angehörigen einer der drei anderen Gruppen stets vollkommen fertil.

Wenn wir also die vier Gruppen als A, B, C und D bezeichnen, so ist jede Kreuzung zwischen A-Pflanzen, B-Pflanzen, C-Pflanzen und D-Pflanzen untereinander steril, während $\mathrm{A} \times \mathrm{B}, \mathrm{A} \times \mathrm{C}, \mathrm{A} \times \mathrm{D} ; \mathrm{B} \times \mathrm{A}, \mathrm{B} \times \mathrm{C}$, $\mathrm{B} \times \mathrm{D} ; \mathrm{C} \times \mathrm{A}, \mathrm{C} \times \mathrm{B}, \mathrm{C} \times \mathrm{D}$ und $\mathrm{D} \times \mathrm{A}, \mathrm{D} \times \mathrm{B}, \mathrm{D} \times \mathrm{C}$ fertil sind.

Um diese Tatsachen sicher zu erweisen, mußten, da nicht alle Kombinationen ausgeführt werden konnten, verschiedene Wege eingeschlagen werden. Zunächst mußte bei einer Anzahl von Pflanzen tunlichst jede Kombination ausgeführt werden, um Sicherheit zu erlangen, daf. auch keine Ausnahme von der Regel vorkam. Zum anderen war es nötig, die Zugehörigkeit möglichst vieler Individuen der $F_{1} z u$ einer der vier Gruppen sicher festzustellen, was leicht dadurch möglich wurde, daß soviel als möglich Individuen mit je zwei sicher ermittelten Angehörigen jeder Gruppe getestet wurden.

Schließlich mußten auch noch möglichst viele verschiedene Individuen überhaupt gekreuzt werden, um zu zeigen, daß nicht doch noch weitere Gruppen vorhanden waren. Ich kann gleich betonen, daß die Gruppenbildung mit einer einzigen etwas zweifelhaften Ausnahme für alle untersuchten Pflanzen stets zutreffend gefunden wurde.

Zur Bekräftigung der hier angeführten Versuchsresultate sehe ich mich nun genötigt, ein möglichst reiches Zahlenmaterial anzuführen. Ich betone, daß ich alle ausgeführten Kreuzungen im folgenden mitteile. Keine ist zur Vermeidung irgend eines Schönheitsfehlers, auch wenn ein Versehen offensichtlich zutage lag oder eine einzelne Bestäubung nicht hatte wiederholt werden können, beiseite gelassen. So hoffe ich, wird meinem Material eine besondere Überzeugungskraft innewohnen. Die Kreuzungen sind sogleich nach den gefundenen Gruppen angeordnet, so daß sie in einfacher Weise zu überblicken sind.

Ich gebe zunächst die Tabellen für die Kreuzungen der 32 Individuen, zwischen denen nahezu jede Kombination ausgeführt wurde. 
In Klammern sind andere, nicht in die Reihe der Kombinationen zwischen den 32 gehörende Bestäubungen mit noch anderen Pflanzen aufgeführt. Zufällig wurden mehr A-Pflanzen herangezogen.

Weiterhin folgen die Tabellen über die Pflanzen, welche durch eine geringere Anzahl von Kreuzungen auf die Zugehörigkeit zu einer oder der anderen Gruppe getestet wurden.

Die Prüfung über das Verhalten bei Selbstbestänbung ist in der ersten Kolonne bei den Tabelleureihen mitgeteilt.

\section{Tabellen für die Bestänbung der 32 beliebig herausgegriffenen}

\section{Individuen.}

Erklärung der Zeichen in den Tabellen:

0 erfolglose Bestäubung, $\mathrm{S}$ schwache Kapselschwellung, + erfolgreiche Bestäubung, In Klammern eingeschlossen sind überzählige, nicht zu den 32 Pflanzen gehörige Kombinationen angeführt. Jeder Bestäubung entspricht ein Zeichen. ! auffällig oder zweifellaft

1. Gruppe $A$.

$124(\mathrm{~A})$.

\begin{tabular}{|c|c|c|c|c|c|c|c|c|c|c|}
\hline \multirow{2}{*}{ 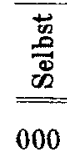 } & \multicolumn{2}{|r|}{ A } & \multicolumn{2}{|c|}{ A } & \multicolumn{2}{|r|}{ B } & \multicolumn{2}{|r|}{$\mathrm{C}$} & \multicolumn{2}{|r|}{ D } \\
\hline & 189 & $S 000$ & 122 & 0000 & 182 & $t+t$ & 92 & $+t+$ & 53 & $+t+t$ \\
\hline & 90 & S 00 & 34 & 0000 & 62 & $+1+$ & 174 & $+t+1$ & 120 & $i+1+1$ \\
\hline & 26 & 000 & & & 89 & + & 83 & $+t+i$ & 176 & $+1+1+t+-1$ \\
\hline & 93 & 00 & & & 85 & $+t+$ & 178 & $+t+t$ & 20 & $0+1+1+$ \\
\hline & 146 & 000 & $(17$ & $00)$ & 148 & $+t+$ & 169 & $t+$ & 50 & $\frac{1}{1}+t$ \\
\hline & $\tilde{51}$ & 000 & & & 163 & $+t+1$ & 113 & $+t+$ & 117 & $t+t$ \\
\hline & 168 & 000 & & & 84 & $+1+t$ & & & & \\
\hline & 185 & 000 & & & & & & & & \\
\hline & 5 & 000000 & & & & & $(28$ & + & 21 & $++1+:$ \\
\hline & 170 & 0000 & & & & & & & & \\
\hline
\end{tabular}

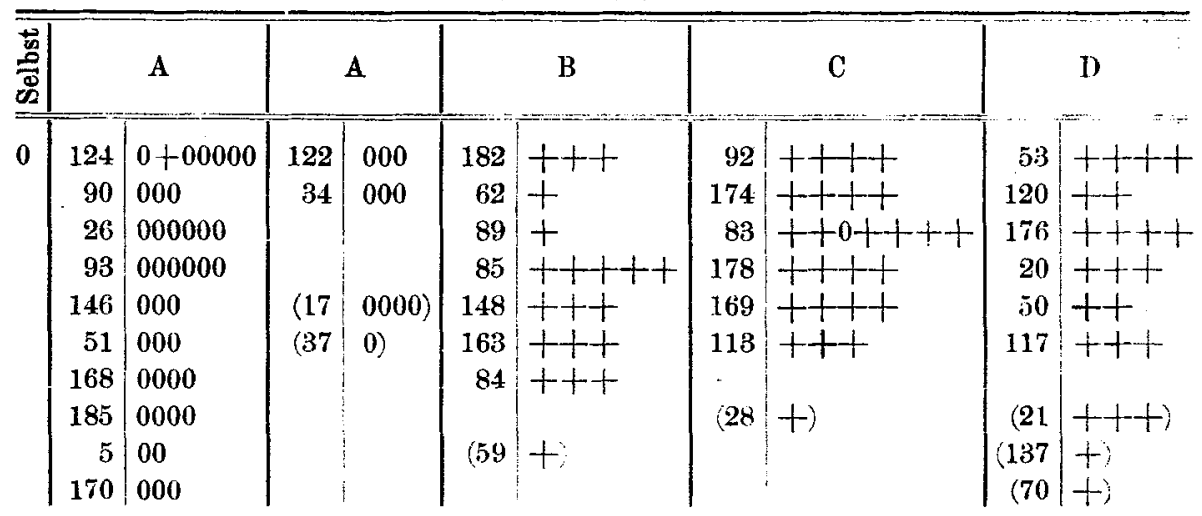


90 (A).

\begin{tabular}{|c|c|c|c|c|c|c|c|c|c|c|}
\hline$?$ & & $A$ & & A & & B & & C & & D \\
\hline 0 & 124 & 000 & 122 & 0000 & 182 & $+t+0+++$ & 92 & $+t+t$ & 53 & $+1++$ \\
\hline & 189 & 000 & 34 & 0000 & 62 & $+1+0$ & 174 & $1+1+$ & 120 & $+0+t+++$ \\
\hline & 26 & 00 & & & 89 & $+1+$ & 83 & $+0+t+t+$ & 176 & $1+t+t$ \\
\hline & 93 & 000 & & & 85 & ++++ & 178 & ++++ & 20 & $++s$ \\
\hline & 146 & 000 & & & 148 & $+t+1$ & 169 & $+0+++$ & 50 & $1+1$ \\
\hline & 51 & 000 & $(17$ & $000)$ & 163 & +++1 & 113 & $+++t$ & 117 & $++t+$ \\
\hline & 168 & 00000 & $(60$ & $0)$ & 84 & $1+1+$ & & & & \\
\hline & 185 & 0000 & 69 & 0) & & & $(28$ & $++t)$ & & \\
\hline & 5 & 0000 & & & $(67$ & + & $(137$ & $t$ & $(21$ & $t+t$ \\
\hline & 170 & 00 & & & & & $(171$ & H) & $(70$ & + \\
\hline
\end{tabular}

26 (A).

\begin{tabular}{|c|c|c|c|c|c|c|c|c|}
\hline $\begin{array}{l}\overrightarrow{0} \\
\stackrel{0}{0} \\
\tilde{D}\end{array}$ & \multicolumn{2}{|c|}{ A } & \multicolumn{2}{|c|}{ A } & \multicolumn{2}{|r|}{ B } & $\mathrm{C}$ & D \\
\hline 00 & 124 & 0000 & 122 & 0000 & 182 & $++++(10+)$ & $92++++$ & $53+++$ \\
\hline & 189 & 0000 & 34 & 000 & 62 & $+1+t+t$ & $174 \mid++0+(10+)$ & $120+0++(10+$ \\
\hline & 90 & 000 & & & 89 & t+t & $831+++$ & $176+t+t$ \\
\hline & 93 & 000 & & & 85 & $+t+$ & $178++$ & $20++++$ \\
\hline & 146 & 0000 & $(17$ & $0000)$ & 148 & ++++ & $169+0++++++$ & $50+++$ \\
\hline & 51 & 000 & $(37$ & 0 & 163 & t+t & $113+++$ & $117+++$ \\
\hline & 168 & 0000 & $(69$ & (0) & 84 & $+t+$ & & \\
\hline & 185 & 0000 & & & & & $(28+)$ & $(21+++)$ \\
\hline & 5 & 000 & & & & & $(128++)$ & \\
\hline & 170 & 0000 & & & & & & \\
\hline
\end{tabular}

93 (A).

\begin{tabular}{|c|c|c|c|c|c|c|c|c|c|c|}
\hline $\begin{array}{l}\overrightarrow{v_{0}} \\
\text { 曾 }\end{array}$ & & A & $A$ & & & B & & $\mathrm{C}$ & & D \\
\hline 0 & 124 & $0 \mathrm{~S} 0$ & 122 & 0 & 182 & $+t+t$ & 92 & + & 53 & +1 \\
\hline & 189 & 0 & 34 & SS & 62 & + & 174 & + & 120 & +1 \\
\hline & 90 & 0000 & & & 89 & + & 83 & ++ & 176 & + \\
\hline & 26 & 000 & & & 85 & + & 178 & + & 20 & $+0+++1$ \\
\hline & 146 & 000 & & & 148 & $0++$ & 169 & + & 50 & + \\
\hline & 51 & 00 & & & 163 & $+0++++$ & 113 & $+\mathrm{s}+++$ & 117 & + \\
\hline & 168 & 0000000 & $(37$ & 0) & 84 & + & & & & \\
\hline & 185 & 0 & $(69$ & 0) & & & (28 & + & $(21$ & + \\
\hline & 5 & 0 & & & & & & & & \\
\hline & 170 & 0 & & & & & & & & \\
\hline
\end{tabular}


Utber die Selbststerilität ron Veronica syriaca.

146 (A).

\begin{tabular}{|c|c|c|c|c|c|c|c|c|c|c|}
\hline 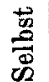 & & A & & & B & & & $\mathrm{C}$ & & D \\
\hline 0 & 124 & $+0+000000$ & 122 & 0 & 182 & + & 92 & + & 53 & $?$ \\
\hline & 189 & 000 & 34 & 0 & 62 & + & 174 & $0+t+t+$ & 120 & + \\
\hline & 90 & 0000 & & & 89 & + & 83 & $t$ & 176 & ++ \\
\hline & 26 & 00 & $(17$ & 0) & $8 \overline{0}$ & + & 178 & + & 20 & $+t$ \\
\hline & 93 & 000 & & & 148 & + & 169 & $t+$ & 50 & ++ \\
\hline & 51 & 0 & & & 163 & + & 113 & + & 117 & ++ \\
\hline & 168 & 00 & & & 84 & + & & & & \\
\hline & 185 & 0 & & & & & $(128$ & $+)$ & $(21$ & $0+++)$ \\
\hline & 5 & 0 & & & & & $(171$ & +1 & (157 & $+)$ \\
\hline & 170 & 0 & & & & & & & $(143$ & + \\
\hline
\end{tabular}

51 (A).

\begin{tabular}{|c|c|c|c|c|c|c|c|c|c|c|}
\hline$\frac{10}{D}$ & \multicolumn{2}{|c|}{ A } & \multicolumn{2}{|c|}{ A } & \multicolumn{2}{|r|}{ B } & \multicolumn{2}{|r|}{$\mathrm{C}$} & \multicolumn{2}{|c|}{ D) } \\
\hline 0 & 124 & 00 & 122 & 0 & 182 & $++t$ & 92 & + & 53 & + \\
\hline & 189 & 000 & 34 & 0 & 62 & ? & 174 & +++ & 120 & + \\
\hline & 90 & 00 & & & 89 & + & 83 & ++ & 176 & + \\
\hline & 26 & 000 & (17 & 0) & $8 \bar{\jmath}$ & + & 178 & + & 20 & + \\
\hline & 93 & 000 & & & 148 & + & 169 & + & 50 & $+t$ \\
\hline & 146 & 00 & & & 163 & + & 113 & $?$ & 117 & + \\
\hline & 168 & 00 & & & 84 & + & & & & \\
\hline & 185 & $?$ & & & & & $(157$ & + & 21 & $+)$ \\
\hline & 5 & 0 & & & 42 & + & (28 & $0 !$ & & \\
\hline & 170 & 0 & & & & & (123) & $t$ & & \\
\hline & & & & & & & 171 & $t$ & & \\
\hline
\end{tabular}

168 (A).

\begin{tabular}{|c|c|c|c|c|c|c|c|c|c|c|}
\hline 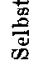 & & $\mathbf{A}$ & $A$ & & & & & $\mathrm{C}$ & & D \\
\hline 0 & 124 & 0 & 122 & 0 & 182 & + & 92 & + & 53 & $++t-0$ \\
\hline & 189 & 0 & 34 & 0 & 62 & + & 174 & $0+++++$ & 120 & $++t+$ \\
\hline & 90 & 0 & & & 89 & + & 83 & & 176 & ++ \\
\hline & 26 & 0 & (17 & 0) & 85 & + & 178 & ++++1 & 20 & + \\
\hline & 93 & 0 & (133 & 0) & 148 & + & 169 & ? & 50 & t \\
\hline & 146 & 0 & & & 163 & + & 113 & $+\dot{+}+++$ & 117 & + \\
\hline & 51 & 0 & & & 84 & + & & & & \\
\hline & 185 & +00000 & & & & & $(28$ & +++1 & (143 & + \\
\hline & 5 & 0 & & & & & & & (21 & + \\
\hline & 170 & 0) & & & & & & & & \\
\hline
\end{tabular}


$185(\mathrm{~A})$.

\begin{tabular}{|c|c|c|c|c|c|c|c|c|c|c|}
\hline 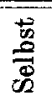 & \multicolumn{2}{|r|}{ A } & \multicolumn{2}{|r|}{ A } & \multicolumn{2}{|r|}{ B } & \multicolumn{2}{|r|}{$\mathrm{C}$} & \multicolumn{2}{|r|}{$\mathrm{D}$} \\
\hline 0 & 124 & 0 & 122 & 0 & 182 & + & 92 & + & 53 & ++ \\
\hline & 189 & 00 & 34 & 0 & 62 & $+t$ & 174 & + & 120 & + \\
\hline & 90 & 0 & & & 89 & $+t$ & 83 & + & 176 & +++ \\
\hline & 26 & 0000 & & & 85 & + & 178 & + & 20 & +++++ \\
\hline & 93 & 0 & $\langle 17$ & $000)$ & 148 & 0 ! & 169 & + & ธั0 & + \\
\hline & 146 & 000 & & & 163 & + & 113 & + & 117 & + \\
\hline & 51 & 0 & & & 81 & + & & & & \\
\hline & 168 & 00 & & & & & 28 & + & (21) & $+)$ \\
\hline & $\check{\jmath}$ & 0 & & & & & & & & \\
\hline & 170 & 00 & & & & & & & & \\
\hline
\end{tabular}

$5(\mathrm{~A})$.

\begin{tabular}{|c|c|c|c|c|c|c|c|c|c|c|}
\hline \multirow{2}{*}{ 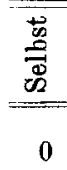 } & \multicolumn{2}{|r|}{ A } & \multicolumn{2}{|c|}{ A } & \multicolumn{2}{|r|}{ B } & \multicolumn{2}{|c|}{$\mathrm{C}$} & \multicolumn{2}{|r|}{ D } \\
\hline & 124 & 00 & 122 & 000 & 182 & + & 92 & + & ธ3 & $0++++$ \\
\hline & 189 & 0 & 34 & 0 . & 62 & + & 174 & $?$ & 120 & + \\
\hline & 90 & 0 & & & 89 & ++ & 83 & + & 176 & $++t+1$ \\
\hline & 26 & SS & $(17$ & 0) & 85 & + & 178 & + & 20 & + \\
\hline & 93 & 00 & & & 148 & + & 169 & + & 50 & + \\
\hline & 146 & 0 & & & 163 & ++ & 113 & + & 117 & + \\
\hline & 51 & 0 & & & 84 & + & & & & \\
\hline & 168 & 0 & & & & & & & $(21$ & $t$ \\
\hline & 185 & 0 & & & & & & & & \\
\hline & 170 & 0 & & & & & & & & \\
\hline
\end{tabular}

$170(\mathrm{~A})$.

\begin{tabular}{|c|c|c|c|c|c|c|c|c|c|c|}
\hline$\frac{1}{8}$ & & A & & A & & B & & $\mathrm{C}$ & & D \\
\hline 0 & 124 & 0 & 122 & 0 & 182 & + & 92 & $0++++$ & 53 & + \\
\hline & 189 & +000 & 34 & 00 & 62 & ++ & 174 & $0+++$ & 120 & + \\
\hline & 90 & 000 & & & 89 & + & 83 & $+0++1$ & 176 & $t$ \\
\hline & 26 & 0 & (17 & 0) & 85 & + & 178 & + & 20 & ++++ \\
\hline & 93 & 0 & (149 & $0)$ & 148 & + & 169 & + & 50 & + \\
\hline & 146 & 00 & & & 163 & + & 113 & + & 117 & + \\
\hline & 51 & 00 & & & 84 & $t$ & & & & \\
\hline & 168 & 00 & & & & & $(28$ & + & (21 & $1+1++1$ \\
\hline & 185 & 000 & & & $(59$ & + & $(171$ & + & $(141$ & !) \\
\hline & 5 & 0 & & & & & $(126$ & +1 & $(137$ & $+\infty$ \\
\hline
\end{tabular}


Über die Selbststerilität von Veronica syriaca.

$122(A)$.

\begin{tabular}{|c|c|c|c|c|c|c|c|c|c|c|}
\hline 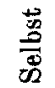 & & A & & A & & B & & $\mathrm{C}$ & & D \\
\hline 0 & 124 & 0 & 5 & 0 & 182 & + & 92 & + & 53 & $0+t+t$ \\
\hline & 189 & 00 & 170 & 00 & 62 & + & 174 & + & 120 & + \\
\hline & 90 & 0 & 34 & $00000 \mathrm{SS}$ & 89 & $t+$ & 83 & + & 176 & $+t+$ \\
\hline & 47 & 000 & & & 85 & + & 178 & + & 20 & + \\
\hline & 26 & 000 & & & 148 & + & 169 & + & 50 & + \\
\hline & 93 & 0 & & & 163 & $+t$ & 113 & + & 117 & + \\
\hline & 146 & 0 & & & 84 & + & & & & \\
\hline & 51 & 0 & & & & & (18 & $+)$ & (21 & $+t-1$ \\
\hline & 168 & 0 & & & & & $(1 ; 37$ & + & $(127$ & +1 \\
\hline & 185 & 0 & & & & & $(171$ & +1 & & \\
\hline
\end{tabular}

34 (A).

\begin{tabular}{|c|c|c|c|c|c|c|c|c|c|c|}
\hline 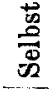 & & A & & A & & B & & $\mathrm{C}$ & & D \\
\hline 0 & 124 & 0 & 170 & 00 & 182 & + & 92 & + & 53 & + \\
\hline & 189 & 0 & 122 & 00000 & 62 & + & 174 & $S$ & 120 & + \\
\hline & 90 & 0 & & & 89 & + & 83 & + & 176 & + \\
\hline & 26 & 000 & & & 85 & + & 178 & + & 20 & + \\
\hline & 93 & 0 & & & 148 & + & 169 & + & 50 & ++ \\
\hline & 146 & 0 & & & 163 & ++ & 113 & ++ & 117 & + \\
\hline & 51 & 0 & & & 84 & + & & & & \\
\hline & 168 & 0 & & & & & & & & \\
\hline & 185 & 00 & & & & & (81) & $+)$ & (21 & + \\
\hline & 5 & 0 & & & & & & & & \\
\hline
\end{tabular}

2. Gruppe B.

182 (B).

\begin{tabular}{|c|c|c|c|c|c|c|c|c|c|c|}
\hline 放 & & A & & A & & B & & C & & D \\
\hline & & & & & & & & & & \\
\hline 0 & 124 & $+t+t$ & 170 & $++t$ & 62 & 0000 & 92 & +++++ & 53 & +++ \\
\hline & 189 & +++ & 122 & $0++$ & 89 & 10000 & 174 & ++ & 120 & +++ \\
\hline & 90 & ++ & 34 & $+t+1$ & 85 & +000000 & 83 & $0+++++$ & 176 & $++t+1$ \\
\hline & 26 & $+++t$ & & & 148 & & 178 & $+t+t$ & 20 & ++ \\
\hline & 93 & $+0+t$ & & & 163 & 00000 & 169 & $+1+1$ & 50 & $++t$ \\
\hline & 146 & $+t$ & & & 84 & 000 & 113 & $+1+t$ & 117 & + \\
\hline & $\therefore 1$ & $+0+t+t+$ & & & & & & & & \\
\hline & 168 & $1+t+$ & & & & & & & $(43$ & $+)$ \\
\hline & 185 & $+1+$ & & & & & & & +4 & + \\
\hline & $\therefore$ & $++t$ & & & & & & & (137) & + \\
\hline
\end{tabular}


62 (B).

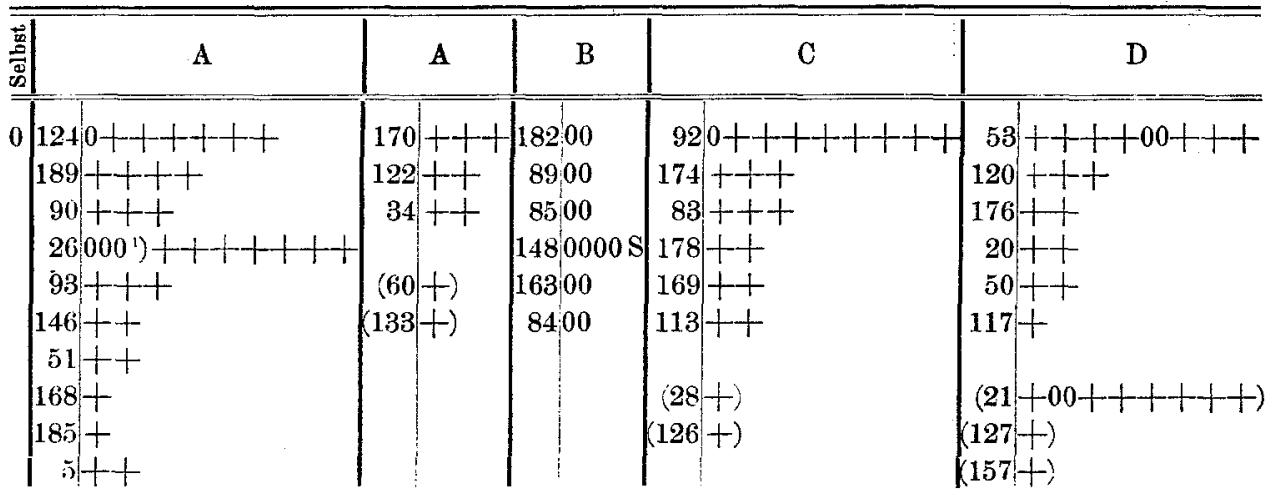

89 (B).

\begin{tabular}{|c|c|c|c|c|c|c|c|c|c|c|}
\hline & & $A$ & & A & & 3 & & $\mathrm{C}$ & & D \\
\hline 0 & 124 & $+1+1$ & 170 & $0+++$ & 182 & 0000 & 92 & $+1+1$ & 53 & ++1 \\
\hline & 189 & $+t$ & 122 & $t+t$ & 62 & 000 & 174 & +1 & 120 & $++t$ \\
\hline & 90 & $+00+++++$ & 34 & + & 85 & 0000 & 83 & $+t+t+t$ & 176 & ++ \\
\hline & 26 & $+1+$ & & & 148 & 00 & 178 & $+t+$ & 20 & $+1+1+1$ \\
\hline & 93 & $+t+$ & & & 163 & 000 & 169 & $+t+$ & 50 & $+t+$ \\
\hline & 146 & $+t+$ & $(17$ & +++1 & 84 & 0000 & 113 & + & 117 & + \\
\hline & 51 & $+0+t$ & & & & & & & 21 & $+t+1)$ \\
\hline & 168 & $t+t$ & & & $(67$ & $0)$ & $r(28$ & $+)$ & $(171$ & + \\
\hline & 185 & $+t+$ & & & & & & & $(77$ & $t$ \\
\hline & 5 & $+0+t+$ & & & & & & & 137 & $t$ \\
\hline
\end{tabular}

85 (B).

\begin{tabular}{|c|c|c|c|c|c|c|c|c|c|c|}
\hline $\begin{array}{l}\overrightarrow{2} \\
\stackrel{3}{3} \\
\vec{n}\end{array}$ & \multicolumn{2}{|r|}{ A } & \multicolumn{2}{|r|}{ A } & \multicolumn{2}{|r|}{ B } & \multicolumn{2}{|r|}{$\mathrm{C}$} & \multicolumn{2}{|r|}{ D } \\
\hline 0 & 124 & $+0++++1$ & 170 & ++ & 182 & 0000000 & 92 & $1+t+$ & 53 & $++t+$ \\
\hline & 189 & ++ & 122 & $+1+$ & 62 & 00000 & 174 & +1 & 120 & $+0++++$ \\
\hline & 90 & $+1+t$ & 34 & $+1+$ & 89 & 00000 & 83 & $++t+$ & 176 & ++ \\
\hline & 26 & $+1++$ & & & 148 & 000 & 178 & $+0+1+$ & 20 & $++t$ \\
\hline & 93 & ++++ & (17 & $++1+1$ & 163 & +000 & 169 & $++t+$ & 50 & +++ \\
\hline & 146 & ++ & $(35)$ & + & 84 & $00+000$ & 113 & ++++ & 117 & $+t+t$ \\
\hline & 51 & $+1+1$ & & & & & $(171$ & $+)$ & & \\
\hline & 168 & +++ & & & (1) & $0)$ & $(28$ & $+)$ & $(21$ & $+t+1$ \\
\hline & 185 & +1 & & & & & $(25$ & $+)$ & (127 & +) \\
\hline & 5 & $+++t$ & & & & & $(33$ & + & & \\
\hline
\end{tabular}

1) Versehentlich zu frülı abgezupft. 
148 (B).

\begin{tabular}{|c|c|c|c|c|c|c|c|c|c|c|}
\hline$\stackrel{\overrightarrow{0}}{\stackrel{\overrightarrow{0}}{0}}$ & & $\mathbf{A}$ & & & & & & & & 9 \\
\hline 0 & 124 & + & 170 & + & 182 & 00 & 92 & + & 53 & + \\
\hline 0 & 189 & + & 122 & $?$ & 62 & 0 & 174 & t. & 120 & $t+$ \\
\hline & 90 & + & 34 & ++ & 89 & 000 & 83 & + & 176 & $+t+1$ \\
\hline & 26 & + & & & 85 & 0 & 178 & + & 20) & $+t$ \\
\hline & 93 & ? & $(17$ & $+)$ & 163 & 00 & 169 & + & 50 & + \\
\hline & 146 & + & & & 84 & 0 & 113 & + & 117 & + \\
\hline & 51 & $+t$ & & & & & (28 & + & & \\
\hline & 168 & + & & & & & (157 & $+)$ & $(143$ & $+)$ \\
\hline & 185 & $+1+$ & & & & & (123 & $t)$ & (21 & + \\
\hline & 5 & & & & & & $(171$ & $t$ & & \\
\hline
\end{tabular}

163 (B).

\begin{tabular}{|c|c|c|c|c|c|c|c|c|c|c|}
\hline $\begin{array}{l}\dot{0} \\
\stackrel{0}{0}\end{array}$ & \multicolumn{2}{|c|}{$\dot{A}$} & \multicolumn{2}{|c|}{ A } & \multicolumn{2}{|c|}{ B } & \multicolumn{2}{|c|}{$\mathrm{C}$} & \multicolumn{2}{|r|}{ D } \\
\hline 0 & 124 & + & 170 & + & 182 & 00 & 92 & + & 53 & + \\
\hline & 189 & + & 122 & + & 62 & 0 & 174 & + & 120 & + \\
\hline & 90 & + & 34 & + & 89 & 0 & 83 & + & 176 & + \\
\hline & 26 & + & & & 85 & 0000 & 178 & + & 20 & $t+t$ \\
\hline & 93 & + & $(17$ & + & 148 & 00 & 169 & + & 50 & + \\
\hline & 146 & + & & & 84 & 00000 & 113 & + & 117 & + \\
\hline & 51 & + & & & & & & & & \\
\hline & 168 & + & & & & & $(28$ & +) & $(21$ & $0+++++1$ \\
\hline & 185 & + & & & & & & & & \\
\hline & 5 & t. & & & & & & & & \\
\hline
\end{tabular}

84 (B).

\begin{tabular}{|c|c|c|c|c|c|c|c|c|c|c|}
\hline 焉 & \multicolumn{2}{|r|}{ A } & \multicolumn{2}{|c|}{ A } & \multicolumn{2}{|r|}{ B } & \multicolumn{2}{|r|}{ C } & \multicolumn{2}{|c|}{$\mathrm{D}$} \\
\hline 0 & 124 & + & 170 & + & 182 & +0000 & 92 & + & 53 & + \\
\hline & 189 & + & 122 & + & 62 & 0 & 174 & + & 120 & $+t$ \\
\hline & 90 & + & 34 & $t+$ & 89 & 0 & 83 & $+t+1$ & 176 & + \\
\hline & 26 & + & & & 85 & +00000 & 178 & + & 20 & $+t$ \\
\hline & 93 & + & $(17$ & + & 148 & 0 & 169 & + & 50 & + \\
\hline & $\begin{array}{r}146 \\
51\end{array}$ & +++ & $(35$ & + & 163 & 000 & 113 & + & 117 & + \\
\hline & $\begin{array}{r}51 \\
768\end{array}$ & $\begin{array}{l}+ \\
+\end{array}$ & & & & & 08 & + & (91 & +1 \\
\hline & 185 & + & & & & & 20 & $+?$ & $\begin{array}{r}(21 \\
137\end{array}$ & $\begin{array}{l}+1 \\
+\end{array}$ \\
\hline & 5 & + & & & & & (174 & +1 & 101 & \\
\hline
\end{tabular}




\section{Gruppe C.}

92 (C)

\begin{tabular}{|c|c|c|c|c|c|c|c|c|c|c|}
\hline 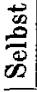 & & A & & A & & B & & $\mathrm{C}$ & & D \\
\hline 0 & 124 & $t+t$ & 170 & $t+t$ & 182 & $0+++t$ & 174 & 0000 & 53 & $++t$ \\
\hline & 189 & $+1+t$ & 122 & ++ & 62 & $t+$ & 83 & 000 & 120 & $+1+$ \\
\hline & 90 & + & 34 & $+t+$ & 89 & $++0++++$ & 178 & $00 \mathrm{~S} \mathrm{~S}$ & 176 & $+10+++1$ \\
\hline & 20 & $+1+1$ & & & 85 & $++t+$ & 169 & 000 & 20 & $+t+$ \\
\hline & 93 & $+1+$ & & & 1.48 & $+t+$ & 113 & 000 & 50 & +1 \\
\hline & 146 & $+t+$ & $(17$ & ++ & 84 & + & & & 117 & $+t+$ \\
\hline & 51 & $+t+$ & & & 163 & ++ & $(28$ & 000 & & \\
\hline & 168 & $+1+$ & & & & & $(171$ & $(+s)$ & $(21$ & +++1 \\
\hline & 185 & $t+$ & & & & & & & $(55$ & + \\
\hline & 5 & +++ & & & & & & & $(137$ & \\
\hline
\end{tabular}

$174(\mathrm{C})$.

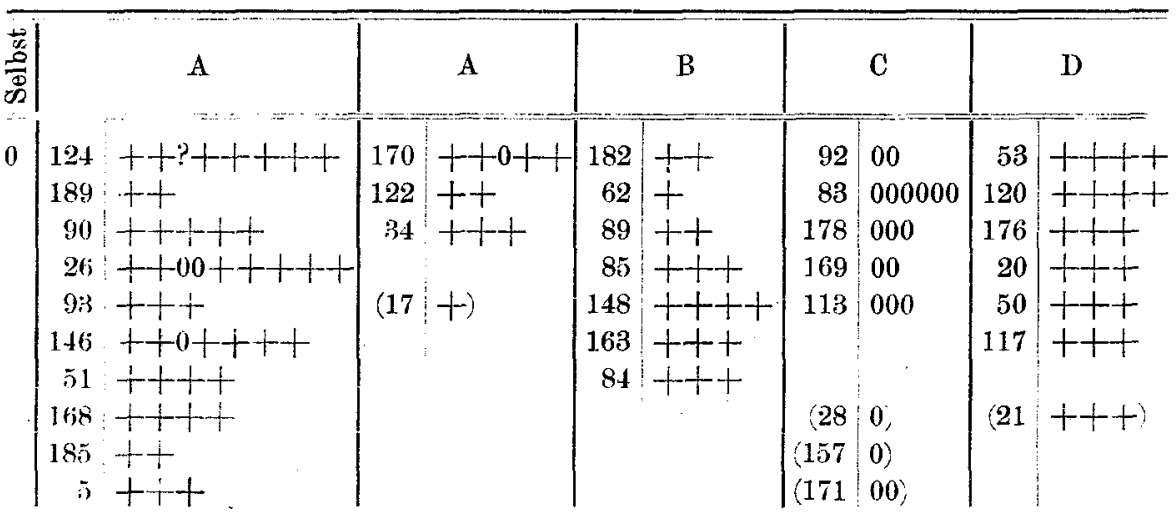

$83<\mathrm{C}$.

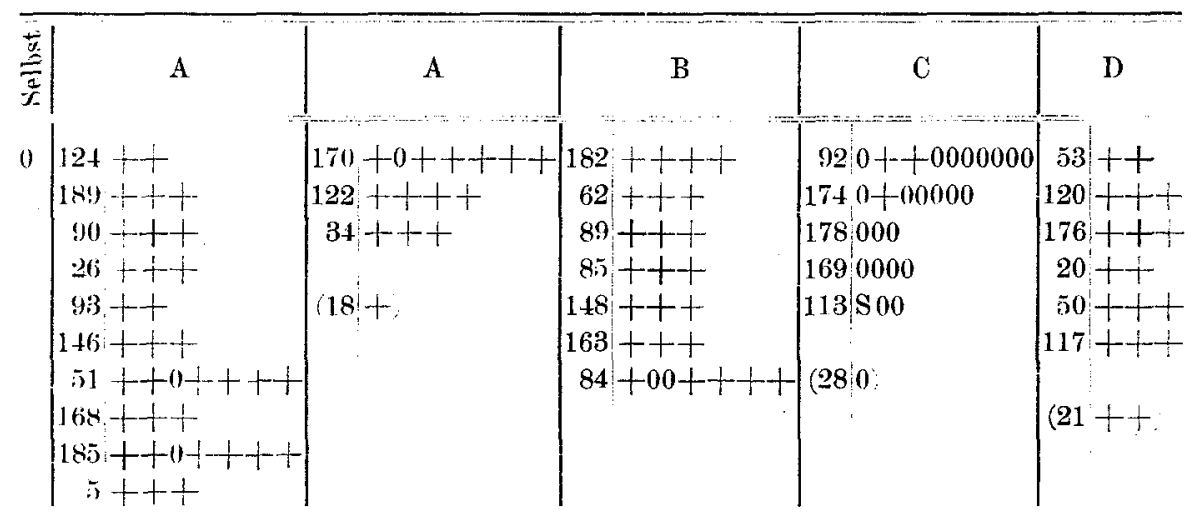


178 (C).

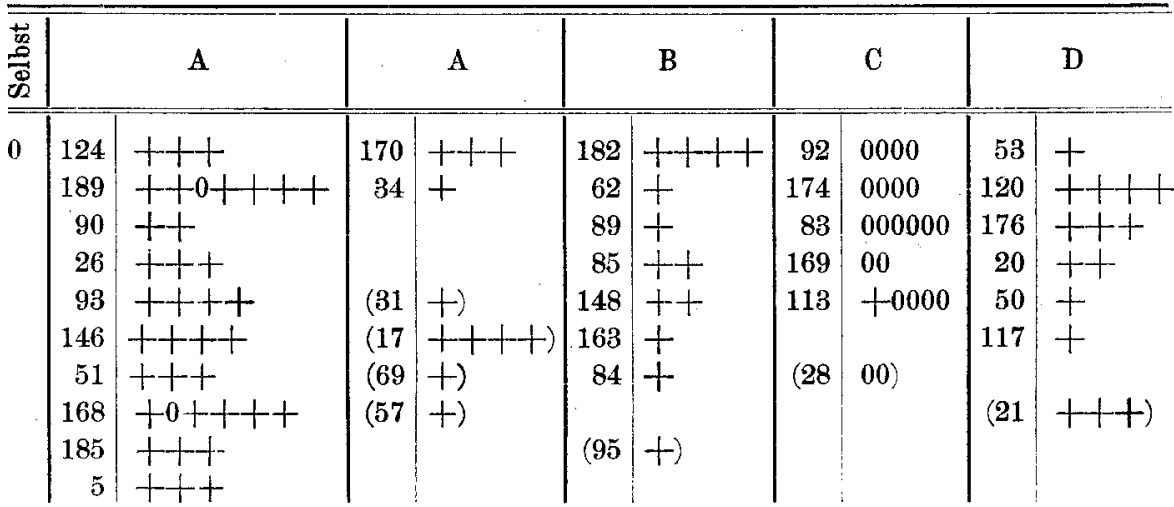

$169(\mathrm{C})$.

\begin{tabular}{|c|c|c|c|c|c|c|c|c|c|c|}
\hline $\begin{array}{l}\overrightarrow{0} \\
\stackrel{0}{0}\end{array}$ & \multicolumn{2}{|c|}{ A } & \multicolumn{2}{|c|}{ A } & \multicolumn{2}{|r|}{ B } & \multicolumn{2}{|c|}{$\mathrm{C}$} & \multicolumn{2}{|c|}{ D } \\
\hline 0 & 124 & + & 170 & + & 182 & + & 92 & 000 & 53 & + \\
\hline & 189 & + & 122 & + & 50 & $+0+$ & 174 & 0 & 120 & + \\
\hline & 90 & + & 34 & + & 89 & + & 83 & 0 & 176 & + \\
\hline & 26 & ++ & & & 85 & + & 178 & 0 & 20 & + \\
\hline & 93 & + & & & 148 & $+t$ & 118 & 0 & 50 & + \\
\hline & 146 & $t-$ & (17 & $+)$ & 163 & + & & & 117 & + \\
\hline & 51 & + & & & 84 & $+t+t$ & & & & \\
\hline & 168 & $t$ & & & & & $(28$ & $+0)$ & (143 & $+)$ \\
\hline & 185 & + & & & & & & & $(21$ & t) \\
\hline & 5 & + & & & & & & & $(127$ & $+)$ \\
\hline
\end{tabular}

113 (C).

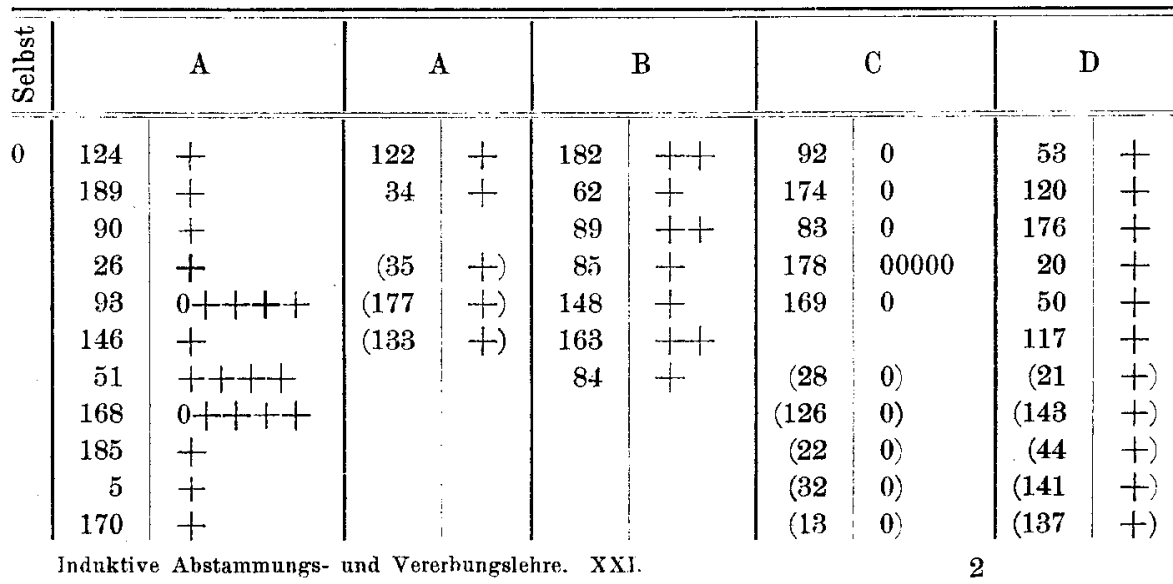




\section{Gruppe D.}

53 (D).

\begin{tabular}{|c|c|c|c|c|c|c|c|c|c|c|}
\hline 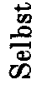 & & A & & & & B & & $\mathrm{C}$ & & \\
\hline 0 & 124 & $+t+1$ & 122 & ? & 182 & ++++ & 92 & $+t$ & 120 & 0 \\
\hline & 189 & $+1+1$ & 34 & + & 62 & + & 174 & $+1+1$ & 176 & 000 \\
\hline & 90 & $t+$ & & & 89 & $+t+t$ & 83 & & 20 & 0 \\
\hline & 26 & $+1+1+1+1$ & (17 & $+)$ & 85 & $+1+t+$ & 178 & $+t+t$ & 50 & 0 \\
\hline & 93 & + & (133 & $+)$ & 148 & + & 169 & + & 117 & 0 \\
\hline & 146 & + & $(31$ & $+)$ & 163 & $t$ & 113 & & $(21$ & $0)$ \\
\hline & 51 & + & & & 84 & + & & & (137 & 0) \\
\hline & 168 & $++1++$ & & & 667 & +1 & (28 & + & $(121$ & 0) \\
\hline & 185 & + & & & $(59$ & $+\infty$ & (130 & + & $(77$ & 0) \\
\hline & 5 & ++1 & & & $(95$ & + & & & (142 & $0)$ \\
\hline & 170 & + & & & $(42$ & + & & & $(55$ & 0) \\
\hline
\end{tabular}

120 (D).

\begin{tabular}{|c|c|c|c|c|c|c|c|c|c|c|}
\hline \multirow{2}{*}{ 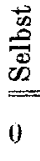 } & \multicolumn{2}{|r|}{ A } & \multicolumn{2}{|c|}{$\Delta$} & \multicolumn{2}{|r|}{ B } & \multicolumn{2}{|c|}{$\mathrm{C}$} & \multicolumn{2}{|r|}{$\mathrm{D}$} \\
\hline & 124 & $t$ & 170 & + & 182 & + & 92 & + & 53 & 0 \\
\hline & 189 & + & 122 & + & 62 & $+0+$ & 174 & + & 176 & 0 \\
\hline & 90 & + & 34 & + & 89 & + & 83 & + & 20 & 0 \\
\hline & 26 & $+1+1+$ & & & 85 & + & 178 & $+t$ & 50 & 0 \\
\hline & 98 & + & (17 & + & 148 & ++ & 169 & + & 117 & 0 \\
\hline & 146 & ++ & (37 & $+)$ & 163 & + & 1.13 & + & (21 & $++000+1)$ \\
\hline & 51 & + & $(69$ & $+)$ & 84 & + & & & (70 & 0) \\
\hline & 168 & $0+1+t$ & $(133$ & $+)$ & & & $(28$ & + & (127 & 0) \\
\hline & 185 & + & & & $(42$ & $+)$ & & & (137 & 0) \\
\hline & 5 & + & & & $(6 \delta$ & $t+t$ & & & $(55$ & $00 \mathrm{~S} 0$ \\
\hline
\end{tabular}

$176(\mathrm{D})$.

\begin{tabular}{|c|c|c|c|c|c|c|c|c|c|c|}
\hline$\stackrel{\vec{b}}{0}$ & & A & & A & & B & & $\mathrm{C}$ & & \\
\hline 0 & 124 & + & 170 & $+1+t$ & 182 & + & 92 & + & 53 & 0 \\
\hline & 189 & + & 122 & + & 62 & + & 174 & + & 120 & 0 \\
\hline & 90 & + & 34 & + & 89 & + & $8: 3$ & + & 20 & (1) \\
\hline & 26 & + & & & 85 & + & 178 & + & 50 & 0 \\
\hline & 93 & + & $(180$ & + & 148 & + & 169 & + & 117 & 0000 \\
\hline & 146 & + & $(133$ & + & 163 & +++0 & 113 & $+0+$ & & \\
\hline & 51 & + & (17 & $+)$ & 84 & $0+++$ & & & (21) & 1) \\
\hline & 168 & + & & & & & & & 65 & 0) \\
\hline & 185 & $t$ & & & & & & & 137 & $\mathrm{SS}$ \\
\hline & 5 & $0++++$ & & & & & & & & \\
\hline
\end{tabular}


20 (D).

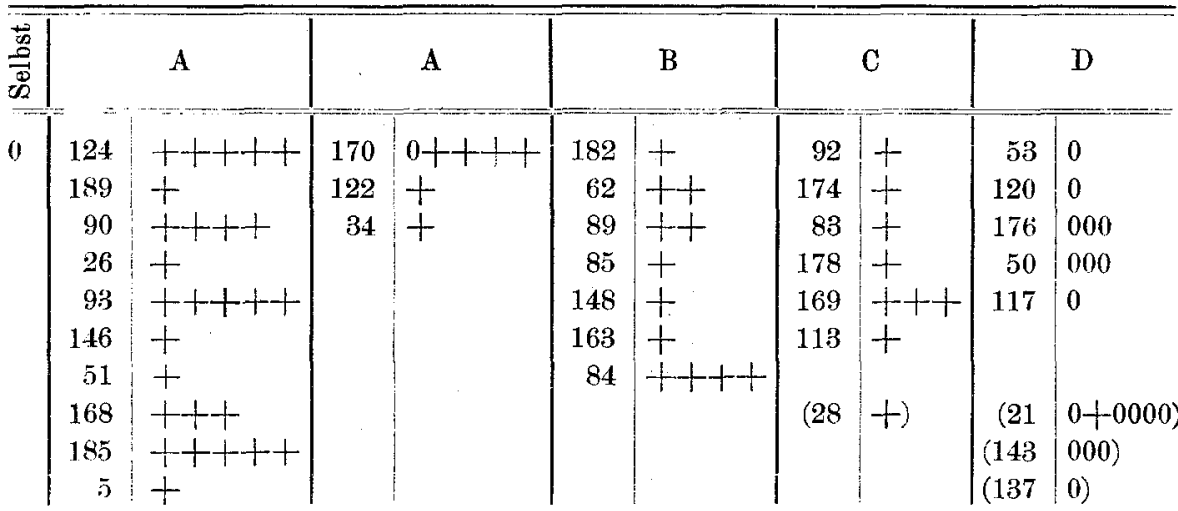

$50(\mathrm{D})$.

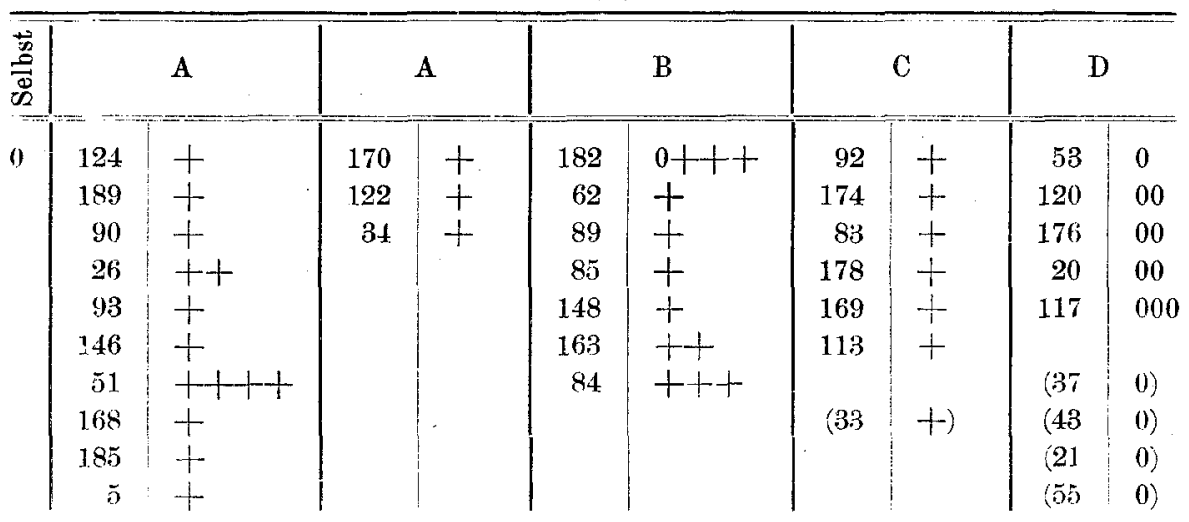

117 (D).

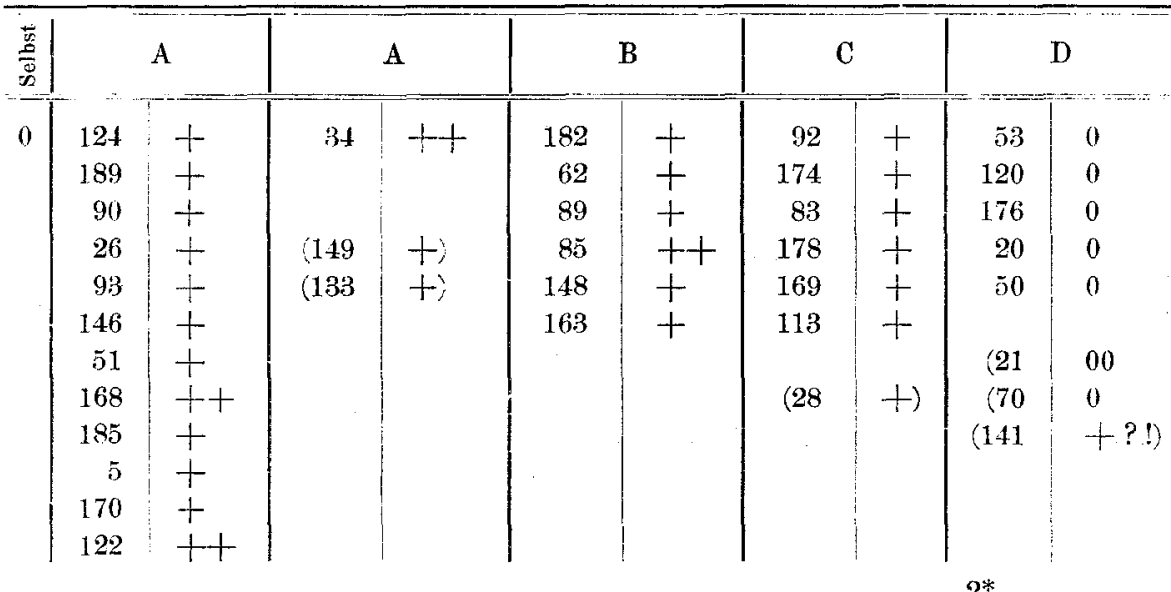


Überblicken wir nun zunächst die Tabellen für diese Bestäubungen unter den 32 willkürlich herangezogenen Pflanzen, so kann es nicht im mindesten zweifelhaft sein, daß wirklich die vier Gruppen vorhanden sind, von denen weiter oben gesprochen wurde. Alle 13 A-Pflanzen sind, miteinander bestäubt, steril, ebenso alle Kombinationen der B-, der C- und der D-Pflanzen je untereinander. Aus der Tabelle ergibt sich zugleich durch Vergleichung, daB alle reziproken Bestäubungen innerhalb dieser Gruppen sich stets gleich verhalten. Von den 992 möglichen Kombinationen wurden 983 ausgeführt, die neun fehlenden konnten aus irgend welchen Gründen nicht hergestellt werden oder waren vergessen worden. In einer großen Anzahl der Fälle wurden die reziproken Bestäubungen nur einmal ansgeführt, wenn sie sowohl untereinander als mit den übrigen Gruppenangehörigen übereinstimmende Resultate ergaben. Oftmals aber wurden auch zwei, drei oder mehr Bestäubungen ausgeführt. Stets wurden die Bestäubungen bei $a b-$ weichenden Resultaten mehrfach wiederholt, bis kein Zweifel über die Natur der Kombination mehr obwalten konnte. Im ganzen wurden zu den 983 Kombinationen 2338 Bestäubungen ausgeführt. Abweichungen von der Erwartung kamen $85 \mathrm{mal}$ vor, d. s. ca. 3,6\%. Diese Abweichungen bestanden $60 \mathrm{mal}$ in einem Versagen der Bestäubung, wo Erfolg zu erwarten gewesen wäre, 11 mal wurde schwache, 14 mal mehr oder weniger weitgehende Kapselbildung beobachtet, wo solche von vornherein nach der Annahme nicht zu erwarten gewesen wäre, also 2,5\% Versager, 1,1\% +-Abweichungen. In allen Fällen konnten die Versager durch zahlreiche Nachkontrollen als Ausnahmsfälle festgestellt werden, da die Kombinationen bei Wiederholung mit ganz wenigen Ausnahmen, wo wieder der eine oder andere Versager darunter war, positiv ausfielen. Es ist demnach wohl kaum zweifelhaft, da $B$ das Ausbleiben des Ansatzes nach diesen Bestäubungen auf mangelhafte Beschaffenheit des Pollens oder der Narbe, unvollständige Bestäubung oder irgend eine andere oben erwähnte Fehlerquelle zurückgeführt werden kann. Auch unter den positiven Abweichungen köunen wohl äußere Fehler darunter gewesen sein, wir werden aber sehen, daß es, wie ich schon erwähnte, durchaus nicht nötig ist, solche zur Erklärung der Abweichungen heranzuziehen. Das ist insofern. von besonderer Bedeutung, als positive Abweichnngen durch Fehler unter den obwaltenden Versuchsbedingungen ja viel schwerer zu erklären wären. 
b) Die Gruppenbildung erwiesen an möglichst zahlreichen $\mathrm{F}_{1}$-Pflanzen.

Nachdem die Gruppenbildung außer Zweifel stand, handelte es sich darum, möglichst viele Individuen der $F_{1}$ auf ihre Gruppenzugehörigkeit zu prüfen. Das war nun nicht mehr so zeitraubend, da jedes Individuum nur mit einigen Individuen jeder Gruppe zu prüfen war, wodurch dann die Gruppenzugehörigkeit festgestellt war. Es gelang mir, von den 198 Exemplaren im ganzen bei 131 Individuen die Gruppenzugehörigkeit festzustellen, mehr erlaubte die Zeit nicht. Ich lasse im folgenden die Zusammenstellung folgen, wobei die zu den 32 erstgeprüften Pflanzen gehörigen Individuen ohne nähere Angaben nur mit der Gruppenbezeichnung wieder mit aufgeführt werden.

\begin{tabular}{|c|c|c|c|c|c|c|c|c|c|}
\hline & Selbst & & A & & B & & $\mathrm{C}$ & & D \\
\hline $1 \mathrm{~B}$ & - & $\begin{array}{r}57 \\
185 \\
146\end{array}$ & $\begin{array}{l}+ \\
+ \\
+\end{array}$ & $\begin{array}{l}85 \\
62\end{array}$ & $\begin{array}{l}00 \\
00\end{array}$ & $\begin{array}{l}92 \\
25\end{array}$ & + & $\begin{array}{r}44 \\
70 \\
117 \\
176 \\
\end{array}$ & $\begin{array}{l}+ \\
+ \\
+ \\
++\end{array}$ \\
\hline $2 \mathrm{~A}$ & 0 & $\begin{array}{r}35 \\
170 \\
185\end{array}$ & $\begin{array}{l}0 \\
0 \\
00\end{array}$ & $\begin{array}{l}148 \\
182\end{array}$ & $\begin{array}{l}++ \\
++\end{array}$ & $\begin{array}{r}22 \\
33 \\
25 \\
13 \\
174 \\
178\end{array}$ & $\begin{array}{l}+ \\
+ \\
+ \\
+ \\
++ \\
0+\end{array}$ & $\begin{array}{r}178 \\
53\end{array}$ & $\begin{array}{l}++ \\
++\end{array}$ \\
\hline $3 \mathrm{~A}$ & - & $\begin{array}{r}2 \\
189 \\
170 \\
185\end{array}$ & $\begin{array}{l}0 \\
0 \\
00 \\
00\end{array}$ & $\begin{array}{l}148 \\
182\end{array}$ & $\begin{array}{l}++ \\
++\end{array}$ & $\begin{array}{r}92 \\
174 \\
178 \\
10\end{array}$ & $\begin{array}{l}+ \\
++ \\
++ \\
+\end{array}$ & $\begin{array}{r}120 \\
53\end{array}$ & $\begin{array}{l}+0 \\
0+\end{array}$ \\
\hline $4 D$ & - & 124 & ++ & 182 & +1 & $\begin{array}{l}178 \\
174\end{array}$ & $\begin{array}{l}++ \\
+\mathrm{s}++\end{array}$ & $\begin{array}{r}176 \\
120 \\
44\end{array}$ & $\begin{array}{l}00 \\
00 \\
00\end{array}$ \\
\hline $5 \mathrm{~A}$ & 0 & & & & & & & & \\
\hline $6 \mathrm{C}$ & 00 & $\begin{array}{r}124 \\
189 \\
170 \\
90\end{array}$ & $\begin{array}{l}++ \\
++ \\
++ \\
0+++\end{array}$ & $\begin{array}{r}182 \\
85\end{array}$ & $\begin{array}{l}++ \\
++\end{array}$ & $\begin{array}{r}92 \\
174 \\
178\end{array}$ & $\begin{array}{l}+-000 \\
000 \\
00\end{array}$ & $\begin{array}{r}120 \\
53 \\
176\end{array}$ & $\begin{array}{l}+0++ \\
+1 \\
++\end{array}$ \\
\hline $8 \mathrm{~B}$ & 00 & $\begin{array}{r}124 \\
90\end{array}$ & $\begin{array}{l}++ \\
++\end{array}$ & $\begin{array}{r}182 \\
-85\end{array}$ & $\begin{array}{l}00 \\
00\end{array}$ & $\begin{array}{l}174 \\
178\end{array}$ & $\begin{array}{l}+t \\
++\end{array}$ & $\begin{array}{r}120 \\
53\end{array}$ & $\begin{array}{l}++ \\
++\end{array}$ \\
\hline $9 \mathrm{C}$ & - & $\begin{array}{r}124 \\
189 \\
90\end{array}$ & $\begin{array}{l}+t \\
+1 \\
t+\end{array}$ & $\begin{array}{r}182 \\
85\end{array}$ & $\begin{array}{l}++ \\
++\end{array}$ & $\begin{array}{r}92 \\
174 \\
178\end{array}$ & $\begin{array}{l}00 \\
00 \\
00\end{array}$ & $\begin{array}{r}120 \\
53 \\
176\end{array}$ & $\begin{array}{l}0+ \\
++ \\
++\end{array}$ \\
\hline
\end{tabular}




\begin{tabular}{|c|c|c|c|c|c|c|c|c|c|}
\hline \multirow[b]{2}{*}{$10 \mathrm{C}$} & \multirow{2}{*}{ Selbst } & \multicolumn{2}{|r|}{ A } & \multicolumn{2}{|r|}{ B } & \multicolumn{2}{|c|}{$\mathrm{C}$} & \multicolumn{2}{|r|}{$\mathrm{D}$} \\
\hline & & $\begin{array}{l}37 \\
51\end{array}$ & $\begin{array}{l}t \\
+t\end{array}$ & $\begin{array}{l}148 \\
182\end{array}$ & $\begin{array}{l}+1 \\
++\end{array}$ & $\begin{array}{r}92 \\
174 \\
178 \\
\end{array}$ & $\begin{array}{l}+(9) \\
00 \\
00\end{array}$ & $\begin{array}{l}176 \\
120\end{array}$ & $\begin{array}{l}+t \\
t+\end{array}$ \\
\hline $11 \mathrm{~A}$ & - & $\begin{array}{r}124 \\
189 \\
90\end{array}$ & $\begin{array}{l}000 \\
00 \\
00\end{array}$ & $\begin{array}{r}182 \\
85 \\
24\end{array}$ & $\begin{array}{l}+ \\
++ \\
+\end{array}$ & $\begin{array}{r}33 \\
92 \\
174 \\
178 \\
\end{array}$ & $\begin{array}{l}t \\
t+1 \\
+t \\
+t\end{array}$ & $\begin{array}{r}44 \\
120 \\
53 \\
27 \\
\end{array}$ & $\begin{array}{l}+ \\
+1 \\
+1 \\
+\end{array}$ \\
\hline $13 \mathrm{C}$ & 00 & $\begin{array}{r}51 \\
180\end{array}$ & $\begin{array}{l}++ \\
+1\end{array}$ & $\begin{array}{l}148 \\
182\end{array}$ & $\begin{array}{l}+\mathrm{S} \\
+\end{array}$ & $\begin{array}{r}32 \\
119 \\
157 \\
178 \\
\end{array}$ & $\begin{array}{l}+(9) \\
0 \\
00 \\
00\end{array}$ & $\begin{array}{l}120 \\
176\end{array}$ & $\begin{array}{l}+t \\
t+\end{array}$ \\
\hline $14 \mathrm{D}$ & - & $\begin{array}{r}124 \\
189 \\
90\end{array}$ & $\begin{array}{l}++ \\
+0++++ \\
++\end{array}$ & $\begin{array}{r}182 \\
85\end{array}$ & $\begin{array}{l}+1 \\
++\end{array}$ & $\begin{array}{r}92 \\
174 \\
178\end{array}$ & $\begin{array}{l}+1 \\
++ \\
s+\end{array}$ & $\begin{array}{r}120 \\
53\end{array}$ & $\begin{array}{l}00 \\
00\end{array}$ \\
\hline $17 \mathrm{~A}$ & 0 & $\begin{array}{r}189 \\
90 \\
124 \\
26 \\
146 \\
5 \\
122 \\
170 \\
34 \\
51 \\
51 \\
168 \\
185 \\
93 \\
\end{array}$ & $\begin{array}{l}0+000 \\
000 \\
0 \\
0 \\
0 \\
0 \\
0 \\
0 \\
00 \\
0 \\
0 \\
0 \\
000 \\
\end{array}$ & \begin{tabular}{r|}
85 \\
148 \\
89 \\
182 \\
62 \\
163 \\
84
\end{tabular} & $\begin{array}{l}0++ \\
+ \\
+ \\
+ \\
+ \\
++4+ \\
+\end{array}$ & \begin{tabular}{r|}
83 \\
92 \\
178 \\
169 \\
28 \\
113 \\
174
\end{tabular} & $\begin{array}{l}+ \\
+ \\
+ \\
+ \\
+ \\
+ \\
+ \\
+ \\
+\end{array}$ & $\begin{array}{r}143 \\
53 \\
120 \\
176 \\
50 \\
20 \\
21\end{array}$ & $\begin{array}{l}0 ! \\
+ \\
+ \\
+ \\
+1 \\
++1 \\
+1 \\
+\end{array}$ \\
\hline $18 \mathrm{~B}$ & - & $\begin{array}{l}185 \\
170\end{array}$ & $\begin{array}{l}+t \\
t+\end{array}$ & $\begin{array}{r}62 \\
148 \\
\end{array}$ & $\begin{array}{l}00 \\
00 \\
\end{array}$ & $\begin{array}{l}169 \\
178 \\
\end{array}$ & $\begin{array}{l}++ \\
++ \\
\end{array}$ & $\begin{array}{r}176 \\
53 \\
\end{array}$ & $\begin{array}{l}++ \\
++ \\
\end{array}$ \\
\hline $21 \mathrm{D}$ & 0 & $\begin{array}{r}122 \\
185 \\
124 \\
90 \\
168 \\
189 \\
1+6 \\
133 \\
26 \\
51 \\
5 \\
170 \\
34 \\
93\end{array}$ & $\begin{array}{l}+ \\
+ \\
+ \\
+ \\
+ \\
+ \\
++++1 \\
+ \\
++ \\
+t \\
+ \\
+++t \\
+ \\
+++\end{array}$ & $\begin{array}{r}85 \\
62 \\
84 \\
148 \\
182 \\
89 \\
174 \\
163\end{array}$ & $\begin{array}{l}+t \\
++t \\
0++t \\
+ \\
0++++ \\
+ \\
+ \\
+\end{array}$ & $\begin{array}{r}92 \\
178 \\
28 \\
113 \\
169\end{array}$ & $\begin{array}{l}+ \\
+ \\
+ \\
+ \\
+t\end{array}$ & $\begin{array}{r}137 \\
127 \\
20 \\
143 \\
53 \\
176 \\
120 \\
55 \\
50 \\
117\end{array}$ & $\begin{array}{l}0 \\
0 \\
0+(100 \\
0 \\
0000 \\
0 \\
0++0 ! \\
0 \\
0 \\
0\end{array}$ \\
\hline
\end{tabular}


Über die Selbststerilität von Veronica syriaca.

\begin{tabular}{|c|c|c|c|c|c|c|c|c|c|}
\hline \multirow{2}{*}{$22 \mathrm{C}$} & \multirow{2}{*}{ Selbst } & \multicolumn{2}{|r|}{ A } & \multicolumn{2}{|r|}{ B } & \multicolumn{2}{|r|}{ C } & \multicolumn{2}{|r|}{ D } \\
\hline & & $\begin{array}{r}57 \\
5 \\
133 \\
124 \\
189 \\
90 \\
\end{array}$ & $\begin{array}{l}+ \\
+ \\
0(1) \\
++ \\
++ \\
++\end{array}$ & $\begin{array}{r}59 \\
67 \\
182 \\
55\end{array}$ & $\begin{array}{l}\frac{1}{i} \\
+ \\
++ \\
++\end{array}$ & $\begin{array}{r}92 \\
174 \\
178\end{array}$ & $\begin{array}{l}00 \\
00 \\
00\end{array}$ & $\begin{array}{r}70 \\
77 \\
142 \\
120 \\
53 \\
27\end{array}$ & $\begin{array}{l}+ \\
+ \\
+ \\
++ \\
++ \\
+\end{array}$ \\
\hline $23 \mathrm{~A}$ & 00 & $\begin{array}{r}51 \\
185\end{array}$ & $\begin{array}{l}0 \\
00\end{array}$ & $\begin{array}{r}24 \\
148 \\
62\end{array}$ & $\begin{array}{l}+ \\
++ \\
+1\end{array}$ & $\begin{array}{r}174 \\
6\end{array}$ & $\begin{array}{l}+1 \\
+1 \\
+1\end{array}$ & $\begin{array}{r}120 \\
43\end{array}$ & $\begin{array}{l}+1 \\
++\end{array}$ \\
\hline $24 \mathrm{~B}$ & 0 & $\begin{array}{r}81 \\
23 \\
2 \\
185 \\
\end{array}$ & $\begin{array}{l}+ \\
+ \\
+ \\
0+\end{array}$ & $\begin{array}{r}10 \\
148 \\
182\end{array}$ & $\begin{array}{l}+! \\
0000 \\
00\end{array}$ & $\begin{array}{l}119 \\
174 \\
178\end{array}$ & $\begin{array}{l}+ \\
++ \\
++\end{array}$ & $\begin{array}{r}43 \\
120 \\
176 \\
43 \\
\end{array}$ & $\begin{array}{l}+ \\
00++00 ! \\
\text { So } \\
++\end{array}$ \\
\hline $25 \mathrm{C}$ & 0 & $\begin{array}{r}124 \\
189 \\
90\end{array}$ & $\begin{array}{l}+1 \\
++ \\
s+\end{array}$ & $\begin{array}{r}1 \\
182 \\
85\end{array}$ & $\begin{array}{l}1 \\
++1 \\
+1\end{array}$ & $\begin{array}{r}92 \\
33 \\
174 \\
178 \\
\end{array}$ & $\begin{array}{l}000 \\
0 \\
00 \\
00\end{array}$ & $\begin{array}{r}120 \\
53\end{array}$ & $\begin{array}{l}++ \\
++\end{array}$ \\
\hline $26 \mathrm{~A}$ & 00 & & & & & & & . & \\
\hline $27 \mathrm{D}$ & - & 11 & $\frac{1}{1}$ & $\begin{array}{r}1 \\
85 \\
59 \\
95 \\
\end{array}$ & $\begin{array}{l}+ \\
+ \\
+ \\
+ \\
+\end{array}$ & $\begin{array}{l}10 \\
22\end{array}$ & + & $\begin{array}{l}\text { nicht } \\
\text { aus- } \\
\text { ge- } \\
\text { führt. }\end{array}$ & \\
\hline $28 \mathrm{C}$ & 0 & $\begin{array}{r}146 \\
51 \\
149 \\
189 \\
26 \\
90 \\
34 \\
124 \\
5 \\
122 \\
\end{array}$ & $\begin{array}{l}+ \\
+ \\
+ \\
+ \\
+ \\
+ \\
+ \\
+ \\
+ \\
+ \\
+ \\
+\end{array}$ & $\begin{array}{r}84 \\
148 \\
85 \\
182 \\
62\end{array}$ & $\begin{array}{l}+ \\
+1 \\
+ \\
+ \\
+ \\
+\end{array}$ & $\begin{array}{r}169 \\
92 \\
33 \\
169 \\
174 \\
178\end{array}$ & $\begin{array}{l}0 \\
00 \\
+! \\
00 \\
0 \\
000\end{array}$ & $\begin{array}{r}20 \\
50 \\
120 \\
53 \\
117\end{array}$ & $\begin{array}{l}+ \\
+ \\
+ \\
+ \\
+\end{array}$ \\
\hline$B 1 \mathrm{~A}$ & - & $\begin{array}{l}185 \\
170\end{array}$ & $\begin{array}{l}00 \\
00\end{array}$ & $\begin{array}{r}95 \\
89 \\
182 \\
148\end{array}$ & $\begin{array}{l}+ \\
+ \\
++ \\
+1\end{array}$ & $\begin{array}{l}169 \\
178\end{array}$ & $\begin{array}{l}1+1 \\
+s\end{array}$ & $\begin{array}{l}176 \\
120\end{array}$ & $\begin{array}{l}+1 \\
+\end{array}$ \\
\hline $32 \mathrm{C}$ & 0 & $\begin{array}{r}31 \\
124 \\
189 \\
90\end{array}$ & $\begin{array}{l}+1 \\
1+1 \\
+1 \\
+1 \\
+1\end{array}$ & $\begin{array}{r}84 \\
182 \\
85\end{array}$ & $\begin{array}{l}+ \\
+1 \\
+1\end{array}$ & $\begin{array}{r}13 \\
22 \\
119 \\
113 \\
92 \\
174 \\
178\end{array}$ & $\begin{array}{l}0 \\
0 \\
0 \\
0 \\
00 \\
00 \\
00\end{array}$ & $\begin{array}{r}70 \\
44 \\
143 \\
117 \\
142 \\
120 \\
.53\end{array}$ & $\begin{array}{l}+ \\
+ \\
+ \\
+ \\
+ \\
+1 \\
++\end{array}$ \\
\hline
\end{tabular}


Lehmann.

\begin{tabular}{|c|c|c|c|c|c|c|c|c|c|}
\hline \multirow[b]{2}{*}{$33 \mathrm{C}$} & \multirow[t]{2}{*}{ Selbst } & \multicolumn{2}{|r|}{ A } & \multicolumn{2}{|r|}{ B } & \multicolumn{2}{|r|}{ C } & \multicolumn{2}{|r|}{$\mathrm{D}$} \\
\hline & & $\begin{array}{r}35 \\
2 \\
185 \\
170\end{array}$ & $\begin{array}{l}+ \\
+ \\
++ \\
+0\end{array}$ & $\begin{array}{r}85 \\
182 \\
148\end{array}$ & $\begin{array}{l}+ \\
++ \\
++\end{array}$ & $\begin{array}{r}25 \\
22 \\
169 \\
178\end{array}$ & $\begin{array}{l}0 \\
0 \\
00 \\
00\end{array}$ & \begin{tabular}{r|r}
44 \\
43 \\
176 \\
120
\end{tabular} & $\begin{array}{l}+ \\
+ \\
++ \\
+-1\end{array}$ \\
\hline $34 \mathrm{~A}$ & 0 & & & & & 10 & & & \\
\hline $35 \mathrm{~A}$ & - & $\begin{array}{r}44 \\
90 \\
2 \\
170 \\
185 \\
\end{array}$ & $\begin{array}{l}0 \\
0 \\
0 \\
00 \\
00\end{array}$ & $\begin{array}{l}182 \\
148\end{array}$ & $\begin{array}{l}++1 \\
++\end{array}$ & $\begin{array}{r}33 \\
174 \\
178\end{array}$ & $\begin{array}{l}+ \\
+1 \\
+1\end{array}$ & $\begin{array}{r}120 \\
53\end{array}$ & $\begin{array}{l}+1 \\
++\end{array}$ \\
\hline $37 \mathrm{~A}$ & 0 & $\begin{array}{r}3 \\
35 \\
124 \\
189 \\
90\end{array}$ & $\begin{array}{l}0 \\
+: \\
00 \\
00 \\
00\end{array}$ & $\begin{array}{r}182 \\
85\end{array}$ & $\begin{array}{l}+++ \\
++\end{array}$ & $\begin{array}{r}178 \\
119 \\
33 \\
157 \\
123 \\
92 \\
174\end{array}$ & $\begin{array}{l}+ \\
+ \\
+ \\
+ \\
+ \\
++ \\
++\end{array}$ & \begin{tabular}{l|}
43 \\
44 \\
55
\end{tabular} & $\begin{array}{l}++ \\
+ \\
+\end{array}$ \\
\hline $42 \mathrm{~B}$ & - & $\begin{array}{r}60 \\
34 \\
90 \\
124 \\
189 \\
\end{array}$ & $\begin{array}{l}+ \\
+ \\
+t+ \\
+t \\
+t\end{array}$ & $\begin{array}{r}182 \\
85\end{array}$ & $\begin{array}{l}00 \\
00\end{array}$ & $\begin{array}{r}92 \\
174 \\
178\end{array}$ & $\begin{array}{l}+t \\
++ \\
+t\end{array}$ & \begin{tabular}{r|}
77 \\
143 \\
117 \\
53 \\
120
\end{tabular} & $\begin{array}{l}+ \\
+ \\
+ \\
++t \\
++t\end{array}$ \\
\hline $43 \mathrm{D}$ & 0 & $\begin{array}{r}37 \\
35 \\
34 \\
124 \\
189 \\
90 \\
\end{array}$ & $\begin{array}{l}+ \\
+ \\
+ \\
++ \\
++ \\
++\end{array}$ & $\begin{array}{r}182 \\
85\end{array}$ & $\begin{array}{l}++1 \\
++\end{array}$ & $\begin{array}{r}178 \\
130 \\
123 \\
92 \\
174 \\
178 \\
\end{array}$ & $\begin{array}{l}+ \\
+ \\
+ \\
++ \\
++ \\
+\end{array}$ & $\begin{array}{r}44 \\
120 \\
53\end{array}$ & $\begin{array}{l}0 \\
00 \\
00\end{array}$ \\
\hline $44 \mathrm{D}$ & - & \begin{tabular}{r|}
37 \\
51 \\
11 \\
5 \\
124 \\
26
\end{tabular} & $\begin{array}{l}+ \\
++ \\
+ \\
+ \\
++ \\
++\end{array}$ & $\begin{array}{r}182 \\
59 \\
24 \\
84\end{array}$ & $\begin{array}{l}++1 \\
+ \\
+ \\
+\end{array}$ & $\begin{array}{r}22 \\
113 \\
13 \\
178\end{array}$ & $\begin{array}{l}+ \\
+ \\
+ \\
++\end{array}$ & \begin{tabular}{r|}
143 \\
120 \\
4 \\
176 \\
43
\end{tabular} & $\begin{array}{l}0 \\
000++00++ \text { ! } \\
00 \\
00 \\
0000\end{array}$ \\
\hline 48 & - & \begin{tabular}{r|}
124 \\
189 \\
90
\end{tabular} & $\begin{array}{l}++ \\
+t \\
++\end{array}$ & $\begin{array}{r}182 \\
85\end{array}$ & $\begin{array}{l}++ \\
++\end{array}$ & $\begin{array}{r}92 \\
174 \\
178\end{array}$ & $\begin{array}{l}++ \\
+t \\
++\end{array}$ & $\begin{array}{r}120 \\
53\end{array}$ & $\begin{array}{l}00 \\
00\end{array}$ \\
\hline $50 \mathrm{D}$ & 0 & & & & & & & & \\
\hline $51 \mathrm{~A}$ & 0 & & & & & & & & \\
\hline $53 \mathrm{D}$ & 0 & & & & & & & & \\
\hline
\end{tabular}




\begin{tabular}{|c|c|c|c|c|c|c|c|c|c|}
\hline & Selbst & & $\mathbf{A}$ & & B & & $\mathrm{C}$ & & D \\
\hline $55 \mathrm{D}$ & 0 & $\begin{array}{r}185 \\
34 \\
133 \\
124 \\
189 \\
90 \\
\end{array}$ & $\begin{array}{l}t \\
+ \\
t \\
+0 \\
+t \\
+t\end{array}$ & $\begin{array}{r}182 \\
89\end{array}$ & $\begin{array}{l}t+ \\
+t\end{array}$ & $\begin{array}{r}130 \\
178 \\
113 \\
92 \\
174\end{array}$ & $\begin{array}{l}+ \\
+1+ \\
+ \\
+t \\
0+\end{array}$ & $\begin{array}{r}127 \\
117 \\
141 \\
120 \\
53\end{array}$ & $\begin{array}{l}0 \\
0 \\
0 \\
++10000 \\
00\end{array}$ \\
\hline $56 \mathrm{C}$ & 0 & $\begin{array}{r}34 \\
51 \\
185\end{array}$ & $\begin{array}{l}+ \\
+t \\
t+\end{array}$ & $\begin{array}{r}148 \\
87 \\
166 \\
85 \\
\end{array}$ & $\begin{array}{l}++ \\
+ \\
+ \\
+0\end{array}$ & $\begin{array}{l}174 \\
178\end{array}$ & $\begin{array}{l}00 \\
00\end{array}$ & $\begin{array}{r}141 \\
147 \\
120 \\
53 \\
\end{array}$ & $\begin{array}{l}+ \\
+ \\
++ \\
++\end{array}$ \\
\hline $57 \mathrm{~A}$ & 0 & $\begin{array}{r}60 \\
37 \\
69 \\
124 \\
189 \\
90 \\
\end{array}$ & $\begin{array}{l}0 \\
0 \\
0 \\
00 \\
00 \\
+00000 \\
\end{array}$ & $\begin{array}{r}1 \\
95 \\
67 \\
59 \\
182 \\
85 \\
\end{array}$ & $\begin{array}{l}+ \\
+ \\
+ \\
+ \\
++ \\
++\end{array}$ & $\begin{array}{r}92 \\
174 \\
178\end{array}$ & $\begin{array}{l}++ \\
++ \\
++\end{array}$ & $\begin{array}{r}70 \\
120 \\
53\end{array}$ & $\begin{array}{l}+1 \\
++ \\
++\end{array}$ \\
\hline $59 \mathrm{~B}$ & 0 & $\begin{array}{r}81 \\
189 \\
26 \\
60 \\
133 \\
185 \\
170\end{array}$ & $\begin{array}{l}+ \\
+ \\
+ \\
+ \\
+ \\
+ \\
+\end{array}$ & $\begin{array}{r}67 \\
62 \\
163 \\
148\end{array}$ & $\begin{array}{l}0 \\
0 \\
0 \\
0\end{array}$ & 123 & + & $\begin{array}{r}70 \\
143 \\
127 \\
77 \\
53 \\
117 \\
142 \\
20\end{array}$ & $\begin{array}{l}+ \\
+ \\
+ \\
+ \\
+ \\
+ \\
+ \\
+\end{array}$ \\
\hline $60 \mathrm{~A}$ & 0 & $\begin{array}{r}5 \\
189 \\
124 \\
90\end{array}$ & $\begin{array}{l}0 \\
000 \\
00 \\
00\end{array}$ & $\begin{array}{r}95 \\
62 \\
42 \\
59 \\
182 \\
85\end{array}$ & $\begin{array}{l}+ \\
+ \\
+ \\
+ \\
++ \\
++\end{array}$ & $\begin{array}{r}92 \\
174 \\
178\end{array}$ & $\begin{array}{l}++ \\
++ \\
++\end{array}$ & $\begin{array}{r}70 \\
120 \\
53\end{array}$ & $\begin{array}{l}s \\
++ \\
+0+t+\end{array}$ \\
\hline $61 \mathrm{C}$ & - & $\begin{array}{r}124 \\
189 \\
90 \\
\end{array}$ & $\begin{array}{l}++ \\
++ \\
++\end{array}$ & $\begin{array}{r}182 \\
85\end{array}$ & $\begin{array}{l}++ \\
++\end{array}$ & $\begin{array}{r}92 \\
174 \\
178 \\
\end{array}$ & $\begin{array}{l}00 \\
00 \\
00 \\
\end{array}$ & $\begin{array}{r}120 \\
53\end{array}$ & $\begin{array}{l}+t \\
+t\end{array}$ \\
\hline $62 \mathrm{~B}$ & 0 & & & & & & & & \\
\hline $63 \mathrm{~B}$ & - & 124 & ++ & 182 & 00 & 174 & ++ & 176 & $+t$ \\
\hline $64 \mathrm{C}$ & 00 & $\begin{array}{r}124 \\
90 \\
\end{array}$ & $\begin{array}{l}++ \\
++\end{array}$ & $\begin{array}{r}182 \\
85 \\
\end{array}$ & $\begin{array}{l}+t \\
++\end{array}$ & $\begin{array}{l}174 \\
178 \\
\end{array}$ & $\begin{array}{l}0 \\
00 \\
\end{array}$ & $\begin{array}{r}120 \\
53 \\
\end{array}$ & $\begin{array}{l}++ \\
++\end{array}$ \\
\hline $65 \mathrm{~B}$ & - & $\begin{array}{r}90 \\
185\end{array}$ & $\begin{array}{l}++ \\
++\end{array}$ & $\begin{array}{r}62 \\
182 \\
-148 \\
\end{array}$ & $\begin{array}{l}0000 \\
00 \\
00 \\
\end{array}$ & $\begin{array}{l}174 \\
178\end{array}$ & $\begin{array}{l}++ \\
++\end{array}$ & $\begin{array}{r}120 \\
43\end{array}$ & $\begin{array}{l}0000++1 \\
++\end{array}$ \\
\hline $66 \mathrm{~B}$ & 0 & $\begin{array}{l}189 \\
133\end{array}$ & $\begin{array}{l}++ \\
+\end{array}$ & $\begin{array}{l}89 \\
62\end{array}$ & $\begin{array}{l}000 \\
0\end{array}$ & 178 & + & $\begin{array}{r}142 \\
77 \\
70 \\
53\end{array}$ & $\begin{array}{l}+ \\
+ \\
+ \\
+\end{array}$ \\
\hline
\end{tabular}




\begin{tabular}{|c|c|c|c|c|c|c|c|c|c|}
\hline \multirow{2}{*}{$67 \mathrm{~B}$} & \multirow{2}{*}{$\frac{\text { Selbst }}{0}$} & \multicolumn{2}{|r|}{ A } & \multicolumn{2}{|r|}{ B } & \multicolumn{2}{|r|}{ C } & \multicolumn{2}{|r|}{ D } \\
\hline & & $\begin{array}{l}189 \\
133\end{array}$ & $\begin{array}{l}++ \\
+\end{array}$ & $\begin{array}{l}89 \\
95 \\
62\end{array}$ & $\begin{array}{l}000 \\
0 \\
0\end{array}$ & 178 & + & $\begin{array}{r}142 \\
70 \\
53 \\
77\end{array}$ & $\begin{array}{l}+ \\
+ \\
+ \\
+\end{array}$ \\
\hline $69 \mathrm{~A}$ & - & $\begin{array}{l}124 \\
185\end{array}$ & $\begin{array}{l}00 \\
00\end{array}$ & $\begin{array}{r}182 \\
85 \\
169\end{array}$ & $\begin{array}{l}++ \\
++ \\
++\end{array}$ & 174 & ++ & $\begin{array}{r}53 \\
176\end{array}$ & + \\
\hline $70 \mathrm{D}$ & 0 & $\begin{array}{r}189 \\
90 \\
37 \\
124 \\
170 \\
\end{array}$ & $\begin{array}{l}+ \\
+- \\
+ \\
++ \\
++\end{array}$ & $\begin{array}{r}59 \\
67 \\
182 \\
85\end{array}$ & $\begin{array}{l}+ \\
+ \\
++ \\
0+\end{array}$ & $\begin{array}{r}32 \\
174 \\
178\end{array}$ & $\begin{array}{l}+ \\
++ \\
++\end{array}$ & $\begin{array}{r}77 \\
43 \\
120 \\
176\end{array}$ & $\begin{array}{l}0 \\
0 \\
00 \\
00\end{array}$ \\
\hline $73 \mathrm{C}$ & - & $\begin{array}{r}124 \\
189 \\
90 \\
\end{array}$ & $\begin{array}{l}++ \\
+1 \\
+t\end{array}$ & $\begin{array}{r}118 \\
182 \\
85 \\
\end{array}$ & $\begin{array}{l}+ \\
++ \\
++ \\
\end{array}$ & $\begin{array}{r}92 \\
174 \\
178 \\
\end{array}$ & $\begin{array}{l}0 \\
00 \\
00 \\
\end{array}$ & $\begin{array}{r}120 \\
53\end{array}$ & $\begin{array}{l}++ \\
++\end{array}$ \\
\hline $77 \mathrm{D}$ & 0 & 133 & + & $\begin{array}{l}67 \\
59\end{array}$ & $\begin{array}{l}+t \\
t\end{array}$ & 22 & + & $\begin{array}{r}143 \\
70 \\
53 \\
121 \\
\end{array}$ & $\begin{array}{l}0 \\
0 \\
0 \\
0 \\
\end{array}$ \\
\hline $78 \mathrm{~A}$ & 0 & 185 & 00 & 148 & +1 & $\begin{array}{l}123 \\
174 \\
\end{array}$ & + & $\begin{array}{l}120 \\
176 \\
\end{array}$ & $\begin{array}{l}+1 \\
+1 \\
+1\end{array}$ \\
\hline $79 \mathrm{~A}$ & - & $\begin{array}{l}124 \\
185 \\
\end{array}$ & $\begin{array}{l}00 \\
0000 \\
\end{array}$ & 182 & ++ & 174 & ++ & 176 & ++ \\
\hline $81 \mathrm{~A}$ & 0 & $\begin{array}{r}57 \\
124 \\
90 \\
189 \\
27 \\
\end{array}$ & $\begin{array}{l}0 \\
00 \\
0 \\
00 \\
+ \\
\end{array}$ & $\begin{array}{r}67 \\
182 \\
85 \\
24\end{array}$ & $\begin{array}{l}+ \\
+t \\
+t \\
t\end{array}$ & $\begin{array}{r}33 \\
174 \\
119 \\
178\end{array}$ & $\begin{array}{l}+ \\
++ \\
+ \\
++\end{array}$ & $\begin{array}{r}142 \\
120 \\
53 \\
14\end{array}$ & $\begin{array}{l}+ \\
++ \\
+ \\
0 !\end{array}$ \\
\hline $83 \mathrm{C}$ & 0 & & & & & & & & \\
\hline $84 \mathrm{~B}$ & 0 & & & & & & & & \\
\hline $85 \mathrm{~B}$ & 0 & & & & & & & & \\
\hline $87 \mathrm{~B}$ & - & $\begin{array}{r}51 \\
185 \\
167 \\
177 \\
78 \\
\end{array}$ & $\begin{array}{l}++ \\
++ \\
+ \\
+ \\
+\end{array}$ & $\begin{array}{l}148 \\
182\end{array}$ & $\begin{array}{l}00 \\
00\end{array}$ & $\begin{array}{r}178 \\
169 \\
56\end{array}$ & $\begin{array}{l}++ \\
t+1 \\
+\end{array}$ & $\begin{array}{l}120 \\
176 \\
181\end{array}$ & $\begin{array}{l}++ \\
++ \\
+\end{array}$ \\
\hline $89 \mathrm{~B}$ & 0 & & & & & & & & \\
\hline $90 \mathrm{~A}$ & 0 & & & & & & & & \\
\hline $91 \mathrm{C}$ & 一 & $\begin{array}{r}124 \\
90 \\
\end{array}$ & $\begin{array}{l}++ \\
++\end{array}$ & $\begin{array}{r}182 \\
85 \\
\end{array}$ & $\begin{array}{l}+t \\
++\end{array}$ & $\begin{array}{l}174 \\
178 \\
\end{array}$ & $\begin{array}{l}00 \\
00\end{array}$ & $\begin{array}{r}120 \\
53\end{array}$ & $\begin{array}{l}+1 \\
+1\end{array}$ \\
\hline $92 \mathrm{C}$ & 0 & & & & & & & & \\
\hline $93 \mathrm{~A}$ & 0 & & & & & & & & \\
\hline
\end{tabular}




\begin{tabular}{|c|c|c|c|c|c|c|c|c|c|}
\hline \multirow[b]{2}{*}{$95 \mathrm{~B}$} & \multirow{2}{*}{$\begin{array}{c}\text { Selbst } \\
0\end{array}$} & \multicolumn{2}{|r|}{ A } & \multicolumn{2}{|r|}{ B } & \multicolumn{2}{|r|}{ C } & \multicolumn{2}{|r|}{ D } \\
\hline & & $\begin{array}{r}60 \\
51 \\
69 \\
189 \\
185 \\
57 \\
\end{array}$ & $\begin{array}{l}+ \\
++ \\
+ \\
+ \\
++ \\
+\end{array}$ & $\begin{array}{r}59 \\
67 \\
85 \\
148\end{array}$ & $\begin{array}{l}0 \\
0 \\
00 \\
00\end{array}$ & $\begin{array}{l}178 \\
174\end{array}$ & $\begin{array}{l}+++ \\
\frac{1}{+}+\end{array}$ & $\begin{array}{r}127 \\
58 \\
120 \\
27\end{array}$ & $\begin{array}{l}+ \\
+++ \\
+0 \\
+\end{array}$ \\
\hline $96 \mathrm{~B}$ & 00 & $\begin{array}{r}51 \\
185 \\
\end{array}$ & $\begin{array}{l}++ \\
++\end{array}$ & $\begin{array}{r}148 \\
62 \\
\end{array}$ & $\begin{array}{l}00 \\
00 \\
\end{array}$ & $\begin{array}{l}178 \\
169 \\
\end{array}$ & $\begin{array}{l}++ \\
0+\end{array}$ & 4 & ++ \\
\hline $100 \mathrm{C}$ & 00 & $\begin{array}{r}185 \\
51 \\
\end{array}$ & $\begin{array}{l}++ \\
++\end{array}$ & $\begin{array}{r}148 \\
85\end{array}$ & $\begin{array}{l}+ \\
0+\end{array}$ & $\begin{array}{l}178 \\
169\end{array}$ & $\begin{array}{l}00 \\
00\end{array}$ & $\begin{array}{l}120 \\
176\end{array}$ & $\begin{array}{l}++ \\
s+\end{array}$ \\
\hline $102 \mathrm{C}$ & - & $\begin{array}{r}124 \\
170 \\
90 \\
\end{array}$ & $\begin{array}{l}++ \\
++ \\
++ \\
\end{array}$ & $\begin{array}{r}182 \\
85\end{array}$ & $\begin{array}{l}++ \\
++\end{array}$ & $\begin{array}{l}174 \\
178\end{array}$ & $\begin{array}{l}00 \\
00\end{array}$ & $\begin{array}{r}120 \\
53 \\
176 \\
\end{array}$ & $\begin{array}{l}++ \\
++ \\
+ \\
\end{array}$ \\
\hline $106 \mathrm{C}$ & $\ldots$ & $\begin{array}{r}124 \\
170 \\
90 \\
\end{array}$ & $\begin{array}{l}+ \\
++ \\
++\end{array}$ & $\begin{array}{r}182 \\
85\end{array}$ & $\begin{array}{l}++ \\
++\end{array}$ & $\begin{array}{l}174 \\
178\end{array}$ & $\begin{array}{l}00 \\
00\end{array}$ & $\begin{array}{r}120 \\
53 \\
176 \\
\end{array}$ & $\begin{array}{l}++ \\
++ \\
+ \\
\end{array}$ \\
\hline $107 \mathrm{D}$ & 00 & $\begin{array}{r}124 \\
189 \\
90\end{array}$ & $\begin{array}{l}+1 \\
+1 \\
+0\end{array}$ & $\begin{array}{r}182 \\
85\end{array}$ & $\begin{array}{l}+t \\
+t\end{array}$ & $\begin{array}{r}92 \\
174 \\
178\end{array}$ & $\begin{array}{l}+1 \\
++ \\
+1\end{array}$ & $\begin{array}{r}120 \\
53 \\
176 \\
43 \\
\end{array}$ & $\begin{array}{l}+0++0 \\
00 \\
00 \\
00\end{array}$ \\
\hline $108 \mathrm{D}$ & 00 & $\begin{array}{r}78 \\
185 \\
51 \\
\end{array}$ & $\begin{array}{l}+ \\
++ \\
0+\end{array}$ & $\begin{array}{l}148 \\
182 \\
166 \\
\end{array}$ & $\begin{array}{l}++ \\
++ \\
+\end{array}$ & $\begin{array}{l}174 \\
178\end{array}$ & $\begin{array}{l}++ \\
++\end{array}$ & $\begin{array}{l}120 \\
176\end{array}$ & $\begin{array}{l}00 \\
00\end{array}$ \\
\hline $110 \mathrm{C}$ & - & $\begin{array}{r}131 \\
90 \\
185 \\
51 \\
\end{array}$ & $\begin{array}{l}+ \\
++ \\
0+ \\
+ \\
\end{array}$ & $\begin{array}{r}85 \\
182 \\
1+8\end{array}$ & $\begin{array}{l}+0 \\
++ \\
+\end{array}$ & $\begin{array}{l}169 \\
178\end{array}$ & $\begin{array}{l}00 \\
00\end{array}$ & $\begin{array}{r}128 \\
176 \\
53\end{array}$ & $\begin{array}{l}+ \\
++ \\
++\end{array}$ \\
\hline $111 \mathrm{C}$ & 00 & $\begin{array}{r}124 \\
90\end{array}$ & $\begin{array}{l}0+ \\
++\end{array}$ & $\begin{array}{r}182 \\
85\end{array}$ & $\begin{array}{l}+1 \\
+\end{array}$ & $\begin{array}{l}174 \\
178\end{array}$ & $\begin{array}{l}00 \\
00\end{array}$ & $\begin{array}{r}120 \\
53\end{array}$ & $\begin{array}{l}++ \\
++\end{array}$ \\
\hline $112 \mathrm{C}$ & 0 & $\begin{array}{r}177 \\
51 \\
185 \\
\end{array}$ & $\begin{array}{l}+ \\
++ \\
+\end{array}$ & $\begin{array}{l}148 \\
182\end{array}$ & $\begin{array}{l}++ \\
+\end{array}$ & $\begin{array}{l}169 \\
174 \\
169 \\
\end{array}$ & $\begin{array}{l}0 \\
00 \\
0 \\
\end{array}$ & $\begin{array}{l}120 \\
176 \\
181 \\
\end{array}$ & $\begin{array}{l}++ \\
++ \\
+ \\
\end{array}$ \\
\hline 1130 & 0 & & & & & & & & \\
\hline $117 \mathrm{D}$ & 0 & & & & & & & & \\
\hline $118 \mathrm{~B}$ & 00 & $\begin{array}{r}124 \\
90\end{array}$ & $\begin{array}{l}++ \\
++\end{array}$ & $\begin{array}{r}182 \\
85 \\
62 \\
\end{array}$ & $\begin{array}{l}0+00 \\
00 \\
00 \\
\end{array}$ & $\begin{array}{l}174 \\
178\end{array}$ & $\begin{array}{l}+t+ \\
t+\end{array}$ & $\begin{array}{r}120 \\
5 ; 3\end{array}$ & $\begin{array}{l}+0++ \\
+0++\end{array}$ \\
\hline $119 \mathrm{C}$ & 0 & $\begin{array}{r}60 \\
57 \\
37 \\
185\end{array}$ & $\begin{array}{l}+ \\
+ \\
+ \\
+\end{array}$ & $\begin{array}{r}182 \\
62 \\
24\end{array}$ & $\begin{array}{l}+1 \\
+1 \\
+\end{array}$ & $\begin{array}{r}13 \\
33 \\
22 \\
169 \\
178 \\
\end{array}$ & $\begin{array}{l}0 \\
0 \\
0 \\
00 \\
00\end{array}$ & $\begin{array}{r}70 \\
43 \\
176 \\
44\end{array}$ & $\begin{array}{l}+ \\
+ \\
+ \\
+\end{array}$ \\
\hline
\end{tabular}




\begin{tabular}{|c|c|c|c|c|c|c|c|c|c|}
\hline & Selbst & & $A$ & & B & & $\mathrm{C}$ & & D \\
\hline $121 \mathrm{D}$ & - & $\begin{array}{r}34 \\
189 \\
51\end{array}$ & $\begin{array}{l}+ \\
++ \\
++\end{array}$ & $\begin{array}{r}84 \\
42 \\
182 \\
85 \\
135 \\
\end{array}$ & $\begin{array}{l}+ \\
+ \\
++ \\
++ \\
0(!)\end{array}$ & $\begin{array}{r}169 \\
126 \\
92 \\
174 \\
178 \\
\end{array}$ & $\begin{array}{l}+ \\
++ \\
+0 \\
++ \\
++\end{array}$ & $\begin{array}{r}127 \\
141 \\
120 \\
53\end{array}$ & $\begin{array}{l}0 \\
0 \\
00 \\
00\end{array}$ \\
\hline $122 \mathrm{D}$ & 0 & & & & & & & & \\
\hline $123 \mathrm{C}$ & 0 & $\begin{array}{l}149 \\
133 \\
170 \\
185\end{array}$ & $\begin{array}{l}+ \\
+ \\
++ \\
++\end{array}$ & $\begin{array}{r}148 \\
62\end{array}$ & $\begin{array}{l}++ \\
++\end{array}$ & $\begin{array}{l}126 \\
112 \\
157 \\
174 \\
178\end{array}$ & $\begin{array}{l}+! \\
0 \\
0 \\
00 \\
00\end{array}$ & $\begin{array}{r}53 \\
141 \\
120\end{array}$ & $\begin{array}{l}++t \\
+ \\
+t\end{array}$ \\
\hline $124 \mathrm{~A}$ & 00 & & & & & & & & \\
\hline $126 \mathrm{C}$ & - & $\begin{array}{l}190 \\
185 \\
170 \\
\end{array}$ & $\begin{array}{l}t \\
+ \\
++\end{array}$ & $\begin{array}{r}166 \\
62 \\
148 \\
\end{array}$ & $\begin{array}{l}+ \\
+0 \\
++\end{array}$ & $\begin{array}{l}169 \\
178\end{array}$ & $\begin{array}{l}00 \\
00\end{array}$ & $\begin{array}{l}176 \\
120\end{array}$ & $\begin{array}{l}+t \\
+t\end{array}$ \\
\hline $127 \mathrm{D}$ & 0 & $\begin{array}{r}185 \\
133 \\
51 \\
\end{array}$ & $\begin{array}{l}+ \\
+ \\
+\end{array}$ & $\begin{array}{l}62 \\
95\end{array}$ & + & & & $\begin{array}{r}21 \\
120 \\
53 \\
\end{array}$ & $\begin{array}{l}0 \\
0 \\
0 \\
\end{array}$ \\
\hline $128 \mathrm{D}$ & 0 & $\begin{array}{r}124 \\
189 \\
90 \\
\end{array}$ & $\begin{array}{l}++ \\
++ \\
++\end{array}$ & $\begin{array}{r}182 \\
85\end{array}$ & $\begin{array}{l}++ \\
++\end{array}$ & $\begin{array}{r}92 \\
174 \\
178 \\
\end{array}$ & $\begin{array}{l}+t \\
++ \\
++ \\
\end{array}$ & $\begin{array}{r}120 \\
53\end{array}$ & $\begin{array}{l}00 \\
00\end{array}$ \\
\hline $130 \mathrm{C}$ & 0 & $\begin{array}{l}133 \\
185 \\
170\end{array}$ & $\begin{array}{l}+ \\
++ \\
++\end{array}$ & $\begin{array}{r}62 \\
182 \\
148\end{array}$ & $\begin{array}{l}+ \\
+t \\
t+\end{array}$ & $\begin{array}{l}123 \\
169 \\
178\end{array}$ & $\begin{array}{l}0 \\
00 \\
00\end{array}$ & $\begin{array}{r}55 \\
137 \\
117 \\
176 \\
120 \\
\end{array}$ & $\begin{array}{l}+ \\
+ \\
+ \\
0+ \\
0+\end{array}$ \\
\hline $131 \mathrm{~A}$ & 0 & $\begin{array}{r}185 \\
51\end{array}$ & $\begin{array}{l}00 \\
00\end{array}$ & $\begin{array}{r}62 \\
148\end{array}$ & $\begin{array}{l}++ \\
++\end{array}$ & $\begin{array}{l}110 \\
169 \\
178 \\
\end{array}$ & $\begin{array}{l}t \\
++ \\
+t\end{array}$ & $\begin{array}{l}128 \\
176\end{array}$ & + \\
\hline $132 \mathrm{C}$ & 00 & $\begin{array}{r}51 \\
185 \\
\end{array}$ & $\begin{array}{l}++ \\
++\end{array}$ & $\begin{array}{l}148 \\
182 \\
\end{array}$ & $\begin{array}{l}++ \\
++\end{array}$ & 178 & 00 & $\begin{array}{l}120 \\
176 \\
\end{array}$ & $\begin{array}{l}++ \\
++\end{array}$ \\
\hline $138 \mathrm{~A}$ & 0 & $\begin{array}{r}93 \\
34 \\
124 \\
189 \\
90\end{array}$ & $\begin{array}{l}000 \\
0 \\
00 \\
00 \\
00\end{array}$ & $\begin{array}{r}62 \\
166 \\
182 \\
85\end{array}$ & $\begin{array}{l}0(!) \\
+ \\
++ \\
0+++++\end{array}$ & $\begin{array}{r}113 \\
130 \\
28 \\
33 \\
123 \\
126 \\
56 \\
92 \\
174 \\
178\end{array}$ & $\begin{array}{l}+ \\
+ \\
+ \\
+ \\
+ \\
+ \\
+ \\
++ \\
+0++++ \\
++\end{array}$ & $\begin{array}{r}11.7 \\
120 \\
137 \\
53 \\
121 \\
55 \\
143 \\
141 \\
43 \\
120 \\
53 \\
\end{array}$ & $\begin{array}{l}++ \\
+ \\
+ \\
+ \\
+ \\
+ \\
+ \\
+ \\
+ \\
++ \\
++\end{array}$ \\
\hline $135 \mathrm{~B}$ & 00 & $\begin{array}{r}185 \\
51\end{array}$ & $\begin{array}{l}++ \\
++\end{array}$ & \begin{tabular}{|r|}
148 \\
62
\end{tabular} & $\begin{array}{l}00 \\
0\end{array}$ & $\begin{array}{r}174 \\
6\end{array}$ & + & 43 & ++ \\
\hline
\end{tabular}


Über die Selbststerilität von Veronica syriaca.

\begin{tabular}{|c|c|c|c|c|c|c|c|c|c|}
\hline & Selbst & & A & & B & & $\mathrm{C}$ & & D \\
\hline $137 \mathrm{D}$ & 0 & $\begin{array}{r}124 \\
133 \\
90\end{array}$ & $\begin{array}{l}+1+ \\
+ \\
+1\end{array}$ & $\begin{array}{r}182 \\
89 \\
85\end{array}$ & $\begin{array}{l}+1+1 \\
+ \\
++\end{array}$ & $\begin{array}{r}178 \\
130 \\
83 \\
174\end{array}$ & $\begin{array}{l}++-1 \\
+ \\
+ \\
++\end{array}$ & $\begin{array}{r}53 \\
20 \\
120\end{array}$ & $\begin{array}{l}000 \\
0 \\
00\end{array}$ \\
\hline $138 \mathrm{D}$ & 00 & $\begin{array}{r}185 \\
51\end{array}$ & $\begin{array}{l}+t \\
+1\end{array}$ & \begin{tabular}{l|}
148 \\
182
\end{tabular} & $\begin{array}{l}+1 \\
+1\end{array}$ & $\begin{array}{l}112 \\
174 \\
178 \\
\end{array}$ & $\begin{array}{l}+ \\
+1 \\
+1\end{array}$ & \begin{tabular}{r|}
43 \\
176
\end{tabular} & $\begin{array}{l}00 \\
00\end{array}$ \\
\hline $139 \mathrm{~B}$ & 0 & $\begin{array}{r}177 \\
51 \\
93 \\
\end{array}$ & $\begin{array}{l}+ \\
++ \\
++ \\
\end{array}$ & $\begin{array}{r}87 \\
148\end{array}$ & $\begin{array}{l}0 \\
00\end{array}$ & $\begin{array}{r}112 ! \\
6\end{array}$ & $\begin{array}{l}+ \\
+1\end{array}$ & \begin{tabular}{r|r}
120 \\
43
\end{tabular} & $\begin{array}{l}0 ! \\
++\end{array}$ \\
\hline $140 \mathrm{C}$ & - & 124 & $+t$ & 182 & $+t$ & 174 & 00 & 176 & + \\
\hline $141 \mathrm{D}$ & 000 & $\begin{array}{r}190 \\
2 \\
90 \\
170 \\
\end{array}$ & $\begin{array}{l}+ \\
+ \\
+t \\
+\end{array}$ & $\begin{array}{r}87 \\
182 \\
148\end{array}$ & $\begin{array}{l}+ \\
+ \\
++\end{array}$ & \begin{tabular}{r|}
157 \\
126 \\
25 \\
178 \\
\end{tabular} & $\begin{array}{l}+ \\
+ \\
+ \\
++ \\
\end{array}$ & $\begin{array}{r}147 \\
176 \\
120 \\
43 \\
\end{array}$ & $\begin{array}{l}0 \\
000 \\
++000 ! \\
000 \\
\end{array}$ \\
\hline $142 \mathrm{D}$ & - & \begin{tabular}{r|}
81 \\
189 \\
5 \\
124 \\
90 \\
\end{tabular} & $\begin{array}{l}+ \\
++1 \\
+ \\
++1 \\
++\end{array}$ & $\begin{array}{r}67 \\
89 \\
182 \\
85\end{array}$ & $\begin{array}{l}+ \\
+ \\
++ \\
++\end{array}$ & \begin{tabular}{r|}
123 \\
22 \\
92 \\
174 \\
178 \\
\end{tabular} & $\begin{array}{l}+1 \\
+ \\
++ \\
++ \\
++\end{array}$ & $\begin{array}{r}53 \\
77 \\
120\end{array}$ & $\begin{array}{l}000 \\
0 \\
++0000\end{array}$ \\
\hline $143 D$ & 0 & $\begin{array}{r}168 \\
5\end{array}$ & $\begin{array}{l}+ \\
+\end{array}$ & \begin{tabular}{r|r}
42 \\
59 \\
148 \\
84
\end{tabular} & $\begin{array}{l}+ \\
+ \\
+ \\
+\end{array}$ & 113 & + & $\begin{array}{r}127 \\
121 \\
176 \\
117 \\
53 \\
20 \\
\end{array}$ & $\begin{array}{l}0 \\
0 \\
0 \\
0 \\
0 \\
00 \\
\end{array}$ \\
\hline $145 \mathrm{C}$ & - & $\begin{array}{r}124 \\
189 \\
90 \\
\end{array}$ & $\begin{array}{l}+ \\
+1 \\
+t \\
\end{array}$ & $\begin{array}{r}182 \\
85\end{array}$ & $\begin{array}{l}++ \\
++\end{array}$ & $\begin{array}{r}92 \\
174 \\
178 \\
\end{array}$ & $\begin{array}{l}00 \\
00 \\
00 \\
\end{array}$ & $\begin{array}{r}120 \\
53\end{array}$ & $\begin{array}{l}+0+-1+- \\
++\end{array}$ \\
\hline $146 \mathrm{~A}$ & 0 & & & & & & & & \\
\hline $1+7 \mathrm{D}$ & 0 & \begin{tabular}{r|r}
124 \\
90
\end{tabular} & $\begin{array}{l}++ \\
++\end{array}$ & $\begin{array}{r}65 \\
166 \\
182 \\
85 \\
\end{array}$ & $\begin{array}{l}+ \\
+ \\
+1 \\
++ \\
\end{array}$ & $\begin{array}{r}157 \\
56 \\
174 \\
178 \\
\end{array}$ & $\begin{array}{l}+ \\
+ \\
1+1 \\
+1 \\
\end{array}$ & $\begin{array}{r}141 \\
120 \\
181 \\
53 \\
\end{array}$ & $\begin{array}{l}0 \\
00 \\
0 \\
00 \\
\end{array}$ \\
\hline $148 \mathrm{~B}$ & 00 & & & & & & & & \\
\hline $149 \mathrm{~A}$ & 0 & \begin{tabular}{l|}
190 \\
185 \\
170
\end{tabular} & $\begin{array}{l}0 \\
00 \\
00\end{array}$ & $\begin{array}{l}182 \\
148 \\
135\end{array}$ & $\begin{array}{l}+t \\
+1 \\
+\end{array}$ & $\begin{array}{l}157 \\
123 \\
169 \\
178 \\
\end{array}$ & $\begin{array}{l}+ \\
+ \\
++ \\
++ \\
\end{array}$ & $\begin{array}{l}141 \\
176 \\
120\end{array}$ & $\begin{array}{l}+ \\
+ \\
++1\end{array}$ \\
\hline $150 \mathrm{D}$ & 00 & $\begin{array}{r}185 \\
51\end{array}$ & $\begin{array}{l}00++ \\
++\end{array}$ & $\begin{array}{r}148 \\
62\end{array}$ & $\begin{array}{l}+t \\
+\end{array}$ & $\begin{array}{r}160 \\
6 \\
112 \\
178\end{array}$ & $\begin{array}{l}+ \\
-1 \\
+ \\
++\end{array}$ & $\begin{array}{r}43 \\
4\end{array}$ & $\begin{array}{l}00 \\
00\end{array}$ \\
\hline
\end{tabular}




\begin{tabular}{|c|c|c|c|c|c|c|c|c|c|}
\hline & Selbst & & A & & B & & C & & D \\
\hline $151 \mathrm{D}$ & 00 & $\begin{array}{r}185 \\
51 \\
\end{array}$ & $\begin{array}{l}++ \\
++ \\
\end{array}$ & $\begin{array}{l}148 \\
182 \\
\end{array}$ & $\begin{array}{l}++ \\
++ \\
\end{array}$ & $\begin{array}{l}178 \\
174 \\
\end{array}$ & $\begin{array}{l}+1 \\
++\end{array}$ & $\begin{array}{r}176 \\
43 \\
\end{array}$ & $\begin{array}{l}00 \\
00 \\
\end{array}$ \\
\hline $152 \mathrm{C}$ & 00 & $\begin{array}{r}124 \\
90 \\
\end{array}$ & $\begin{array}{l}++ \\
0+\end{array}$ & $\begin{array}{r}182 \\
85 \\
\end{array}$ & $\begin{array}{l}++ \\
++\end{array}$ & $\begin{array}{l}174 \\
178\end{array}$ & $\begin{array}{l}00 \\
00\end{array}$ & $\begin{array}{r}120 \\
53 \\
\end{array}$ & $\begin{array}{l}++ \\
++\end{array}$ \\
\hline $153 \mathrm{~B}$ & - & $\begin{array}{r}51 \\
180 \\
\end{array}$ & $\begin{array}{l}+1 \\
+1 \\
\end{array}$ & $\begin{array}{r}148 \\
85 \\
\end{array}$ & $\begin{array}{l}00 \\
00 \\
\end{array}$ & $\begin{array}{l}174 \\
178 \\
\end{array}$ & $\begin{array}{l}+ \\
++ \\
\end{array}$ & $\begin{array}{r}120 \\
53 \\
\end{array}$ & $\begin{array}{l}+1 \\
++\end{array}$ \\
\hline $154 \mathrm{~A}$ & 00 & $\begin{array}{r}185 \\
51\end{array}$ & $\begin{array}{l}00 \\
00\end{array}$ & $\begin{array}{r}118 \\
148 \\
62\end{array}$ & $\begin{array}{l}+ \\
++ \\
++\end{array}$ & $\begin{array}{r}91 \\
73 \\
169 \\
174 \\
\end{array}$ & $\begin{array}{l}+ \\
+ \\
++1 \\
+\end{array}$ & $\begin{array}{l}176 \\
120\end{array}$ & $\begin{array}{l}++ \\
++\end{array}$ \\
\hline $156 \mathrm{D}$ & 0 & $\begin{array}{r}185 \\
51\end{array}$ & $\frac{1+}{+1}$ & $\begin{array}{r}148 \\
62\end{array}$ & $\begin{array}{l}++ \\
++\end{array}$ & $\begin{array}{r}178 \\
6\end{array}$ & $\begin{array}{l}++ \\
++\end{array}$ & $\begin{array}{r}151 \\
108 \\
43 \\
\end{array}$ & $\begin{array}{l}0 \\
0 \\
++00 \\
\end{array}$ \\
\hline $157 \mathrm{C}$ & 0 & $\begin{array}{r}149 \\
180 \\
23 \\
167 \\
190 \\
133 \\
51 \\
185 \\
\end{array}$ & $\begin{array}{l}+ \\
+ \\
+ \\
+ \\
+ \\
+ \\
++ \\
++\end{array}$ & $\begin{array}{l}166 \\
148 \\
182\end{array}$ & $\begin{array}{l}+ \\
++ \\
++\end{array}$ & $\begin{array}{r}123 \\
56 \\
174 \\
169\end{array}$ & $\begin{array}{l}0 \\
0 \\
00 \\
00\end{array}$ & $\begin{array}{r}147 \\
141 \\
120 \\
53\end{array}$ & $\begin{array}{l}+ \\
+ \\
0+ \\
++\end{array}$ \\
\hline $160 \mathrm{C}$ & - & \begin{tabular}{r|r}
51 \\
185
\end{tabular} & $\begin{array}{l}++ \\
t+\end{array}$ & $\begin{array}{l}148 \\
182\end{array}$ & $\begin{array}{l}S+ \\
++\end{array}$ & $\begin{array}{r}56 \\
178 \\
169 \\
\end{array}$ & $\begin{array}{l}00 \\
00 \\
00 \\
\end{array}$ & $\begin{array}{l}120 \\
176\end{array}$ & $\begin{array}{l}+t \\
++\end{array}$ \\
\hline $163 \mathrm{~B}$ & 0 & & & & & & & & \\
\hline $164 \mathrm{C}$ & 0 & $\begin{array}{r}185 \\
51 \\
\end{array}$ & $\begin{array}{l}++ \\
++\end{array}$ & $\begin{array}{l}148 \\
182 \\
\end{array}$ & $\begin{array}{l}++ \\
+ \\
\end{array}$ & 178 & 00 & $\begin{array}{r}120 \\
43 \\
\end{array}$ & $\begin{array}{l}++ \\
++\end{array}$ \\
\hline $165 \mathrm{~B}$ & - & \begin{tabular}{r|r}
26 \\
170 \\
146
\end{tabular} & $\begin{array}{l}+ \\
+ \\
++\end{array}$ & $\begin{array}{r}153 \\
182 \\
85 \\
148 \\
\end{array}$ & $\begin{array}{l}0 \\
00 \\
00 \\
00 \\
\end{array}$ & $\begin{array}{l}174 \\
178\end{array}$ & $\begin{array}{l}++ \\
++\end{array}$ & $\begin{array}{l}120 \\
176\end{array}$ & $\begin{array}{l}++ \\
++\end{array}$ \\
\hline $166 \mathrm{~B}$ & 0 & \begin{tabular}{r|r}
177 \\
34 \\
124 \\
90 \\
185 \\
\end{tabular} & $\begin{array}{l}+ \\
+ \\
0+ \\
++ \\
++\end{array}$ & $\begin{array}{r}182 \\
85 \\
148\end{array}$ & $\begin{array}{l}00 \\
00 \\
000\end{array}$ & $\begin{array}{l}174 \\
178\end{array}$ & $\begin{array}{l}++++ \\
0+++\end{array}$ & $\begin{array}{r}108 \\
147 \\
128 \\
120 \\
53 \\
\end{array}$ & $\begin{array}{l}+ \\
+ \\
+ \\
000000+(1) \\
++ \\
\end{array}$ \\
\hline $167 \mathrm{~A}$ & 00 & \begin{tabular}{r|}
170 \\
185 \\
78
\end{tabular} & $\begin{array}{l}00 \\
00 \\
0\end{array}$ & $\begin{array}{r}87 \\
166 \\
148 \\
182 \\
135\end{array}$ & $\begin{array}{l}+ \\
+ \\
++ \\
+1 \\
+\end{array}$ & $\begin{array}{r}157 \\
.56 \\
112 \\
174 \\
178\end{array}$ & $\begin{array}{l}+ \\
+ \\
+ \\
++ \\
++\end{array}$ & $\begin{array}{r}141 \\
120 \\
53 \\
150\end{array}$ & $\begin{array}{l}+ \\
++ \\
++ \\
+\end{array}$ \\
\hline
\end{tabular}




\begin{tabular}{|c|c|c|c|c|c|c|c|c|c|}
\hline \multirow[b]{2}{*}{$168 \mathrm{~A}$} & \multirow{2}{*}{$\begin{array}{c}\text { Selbst } \\
0\end{array}$} & \multicolumn{2}{|r|}{$\mathbf{A}$} & \multicolumn{2}{|r|}{ B } & \multicolumn{2}{|r|}{$\mathrm{C}$} & \multicolumn{2}{|r|}{ D } \\
\hline & & & & & . & & & & \\
\hline $169 \mathrm{C}$ & 0 & & & & & & & & \\
\hline $170 \mathrm{~A}$ & 00 & & & & & & & & \\
\hline $173 \mathrm{~A}$ & 00 & $\begin{array}{r}185 \\
51\end{array}$ & $\begin{array}{l}0 \\
00\end{array}$ & $\begin{array}{r}148 \\
62\end{array}$ & $\begin{array}{l}+1 \\
+1\end{array}$ & $\begin{array}{l}174 \\
178\end{array}$ & $\begin{array}{l}+1 \\
+1\end{array}$ & $\begin{array}{r}120 \\
43\end{array}$ & $\begin{array}{l}++ \\
++\end{array}$ \\
\hline $174 \mathrm{C}$ & 0 & & & & & & & & \\
\hline $176 \mathrm{D}$ & 0 & & & & & & & & \\
\hline $177 \mathrm{~A}$ & - & $\begin{array}{r}90 \\
185\end{array}$ & $\begin{array}{l}00 \\
00\end{array}$ & $\begin{array}{l}182 \\
148\end{array}$ & $\begin{array}{l}++ \\
+t\end{array}$ & $\begin{array}{l}174 \\
178\end{array}$ & $\begin{array}{l}++ \\
++\end{array}$ & $\begin{array}{l}141 \\
120 \\
176\end{array}$ & $\begin{array}{l}+ \\
\text { s+t } \\
++\end{array}$ \\
\hline $178 \mathrm{C}$ & 0 & & & & & & & & \\
\hline $179 \mathrm{~B}$ & 00 & $\begin{array}{r}51 \\
185\end{array}$ & $\begin{array}{l}++ \\
++\end{array}$ & $\begin{array}{l}148 \\
182\end{array}$ & $\begin{array}{l}00 \\
00\end{array}$ & $\begin{array}{l}174 \\
178\end{array}$ & $\begin{array}{l}++ \\
++\end{array}$ & $\begin{array}{r}120 \\
176 \\
4\end{array}$ & $\begin{array}{l}0000 ! ! \\
++ \\
++\end{array}$ \\
\hline $180 \mathrm{~A}$ & () & $\begin{array}{r}185 \\
51\end{array}$ & $\begin{array}{l}00 \\
00\end{array}$ & $\begin{array}{r}166 \\
148 \\
85 \\
\end{array}$ & $\begin{array}{l}+ \\
++ \\
0+\end{array}$ & $\begin{array}{r}56 \\
178\end{array}$ & + & $\begin{array}{l}120 \\
176\end{array}$ & $\begin{array}{l}++ \\
++\end{array}$ \\
\hline $181 \mathrm{~J}$ & - & $\begin{array}{r}51 \\
185\end{array}$ & $\begin{array}{l}++ \\
+0\end{array}$ & $\begin{array}{l}182 \\
148\end{array}$ & $\begin{array}{l}+t \\
+\end{array}$ & $\begin{array}{l}112 \\
178 \\
169 \\
\end{array}$ & $\begin{array}{l}+ \\
++ \\
++\end{array}$ & $\begin{array}{r}120 \\
176 \\
43 \\
\end{array}$ & $\begin{array}{l}+++0+! \\
00000 \\
000\end{array}$ \\
\hline $182 \mathrm{~B}$ & 0 & & & & & & & & \\
\hline $185 \mathrm{~A}$ & 0 & & & & & & & & \\
\hline $187 \mathrm{~B}$ & 00 & $\begin{array}{r}185 \\
51\end{array}$ & + & $\begin{array}{r}148 \\
62\end{array}$ & $\begin{array}{l}00 \\
00\end{array}$ & $\begin{array}{r}178 \\
6\end{array}$ & $\begin{array}{l}++ \\
++\end{array}$ & $\begin{array}{r}43 \\
120 \\
\end{array}$ & $\begin{array}{l}+1 \\
++\end{array}$ \\
\hline $189 \mathrm{~A}$ & 0 & & & & & & & & \\
\hline $190 \mathrm{~A}$ & - & $\begin{array}{l}170 \\
185\end{array}$ & $\begin{array}{l}00 \\
00\end{array}$ & $\begin{array}{l}148 \\
163\end{array}$ & $\begin{array}{l}++ \\
++\end{array}$ & $\begin{array}{l}174 \\
178\end{array}$ & + & $\begin{array}{l}120 \\
176\end{array}$ & $\begin{array}{l}++ \\
++\end{array}$ \\
\hline
\end{tabular}

Wenn man diese Tabellen betrachtet, so fällt zunächst auch hier in jedem Falle die klare Gruppenzugehörigkeit auf. In erster Linie fand sich keine einzige Pflanze, welche etwa mit Individuen aus allen vier Gruppen immer fruchtbare Kapseln ergeben hätte, oder aber mit zwei Gruppen unfruchtbar gewesen wäre. Allerdings war die Zahl der Abweichungen hier etwas größer, als bei den sorgfältig durchgeprüften 32 ersten Pflanzen. Zunächst liegt das sicher daran, daß zu diesen Bestäubungen die Testpflanzen zumeist schon erheblich älter und oft schon etwas geschädigt waren, daß weiter in diese Bestäubungszeit häufigere Regemperioden einfielen, welche stets dieZuverlässigkeit etwas abschwächen. Weiter konnten nicht alle etwas zweifelhaften Verbindungen immer wiedel nachgeprüft werden, da das Material dazu nicht mehr in günstigem 
Zustande war. Stets aber ließ sich durch eine Reihe von Kombinationen die einwandfreie Zugehörigkeit zu einer oder der anderen Gruppe erweisen. Das gelang auch bei der einzigen, in verschiedener Hinsicht etwas zweifelhaften Pflanze, Nr. 120, welche wir ja schon unter unseren ersten 32 Pflanzen der Gruppe D zuweisen konnten. Nur in einigen wenigen Kombinationen (mit B 166, 65 und mit D 21, 55, 142) kam es hier zu etwas unerwarteten Ergebnissen, denen wir aber als einzigen Ausnahmen einstweilen keine besondere Bedeutung beilegen, wenngleich sie weiter im Auge behalten werden müssen. Wir wollen uns indessen nun noch über die Anzahl der den verschiedenen Gruppen zuzuzählenden Individuen Aufklärung verschaffen. Es gehören zu

Gruppe A $\quad$ B $\quad$ C $\quad$ D

$\begin{array}{lllll}35 & 27 & 37 & 31 & \text { Individuen. }\end{array}$

Ich möchte uicht urteilen, ob die vier Gruppen theoretisch als gleichgroß anzunehmen wären, ob B und D kleiner sind, als die anderen. Ehe weitere Kreuzungen unter bestimmten, später zu betrachtenden Gesichtspunkten angestellt sein werden, ist das auch fast noch ohne Belang.

\section{Feststellung der Gruppenbildung durch Isolation der vier Gruppen an weit voneinander entfernten Plätzen im Freien.}

Zweifelsfrei ist zwar die Gruppeneinteilung an sich schon dureh die vorhergehenden Bestäubungen. Es war indessen die Möglichkeit, diese Gruppeneinteilung noch weiter auf ihre Richtigkeit zu prüfen. Wie schon erwähnt, kommt $V$. syriaca bei uns weder wild noch verwildert vor' und wird auch nirgends in Gärten kultiviert. Bei Kultur im Freien kommt es aher durch Kreuzbestänbung zu fast vollständigem Fruchtansatz, wie ich regelmäßig beobachtete, wenn eine Anzahl beliebig herausgegriffener Individuen gemeinsam kultiviert wurde. Wenn aber nun Angehörige der vier Gruppen an räumlich soweit voneinander getrennten Plïtzeu in Freien kultiviert würden, daß keine Übertragung des Pollens durch Insekten vom eiven zum anderen stattfinden kaun, so dürfte es, wenn wirklich die einzelnen Individuen jeder Gruppe untereinander keine Samen hervorbringen, nirgends zur Bildung von fruchtbaren Kapseln kommen. Ich bin nun so vorgegangen und habe von jeder Gruppe eine größere Anzahl Pflanzen an mindestens $1 \mathrm{~km}$ voneinander entfernten Plätzen im Freien aufgestellt. Es kamen zur Aufstellung:

Gruppe A in meinem Privatgarten in Lustnau, Gruppe $B$ in einem Garten nahe dem Westbahnhof Tübingen, Gruppe $\mathrm{C}$ im Garten des Herrn cand. Fischer in Wanuweil, $9 \mathrm{~km}$ von Tübingen, 
Gruppe D im Garten der Frau Professor. Vöchting, in der äaßeren Gartenstraße in Tübingen.

An den genannten Plätzen verblieben die Pflanzen durch drei bis vier Wochen und hielten sich daselbst, mit einigen wenigen Ausnahmen vollständig frisch und waren bei Abbrechung des Versuches noch in Blüte. Kontrollexemplare ans verschiedenen Gruppen wurden in der gleichen Zeit im botanischen Garten in Freien kultiviert und setzten stets sehr reichlich Kapseln mit vielen reifen Samen an.

Betrachten wir zunächst an zwei Beispielen, in welcher Zeit und in welchem Grade es bei diesen letzteren Pflanzen zu Frucht und Samenansatz gekommen ist.

Am 21. Juni wurden von Nr. 9 (Gruppe C) und Nr. 142 (Gruppe D) sämtliche abgeblühte und offene Blüten und Kapseln abgezupft und beide Pflanzen dann frei im botanischen Garten aufgestellt. Am 15. Juli wurde dann eine Reihe von $Z$ weigen jeder Pflanze von der Blüte rückwärts auf die Ansatzverhältnisse hin studiert. Es ergab sich:

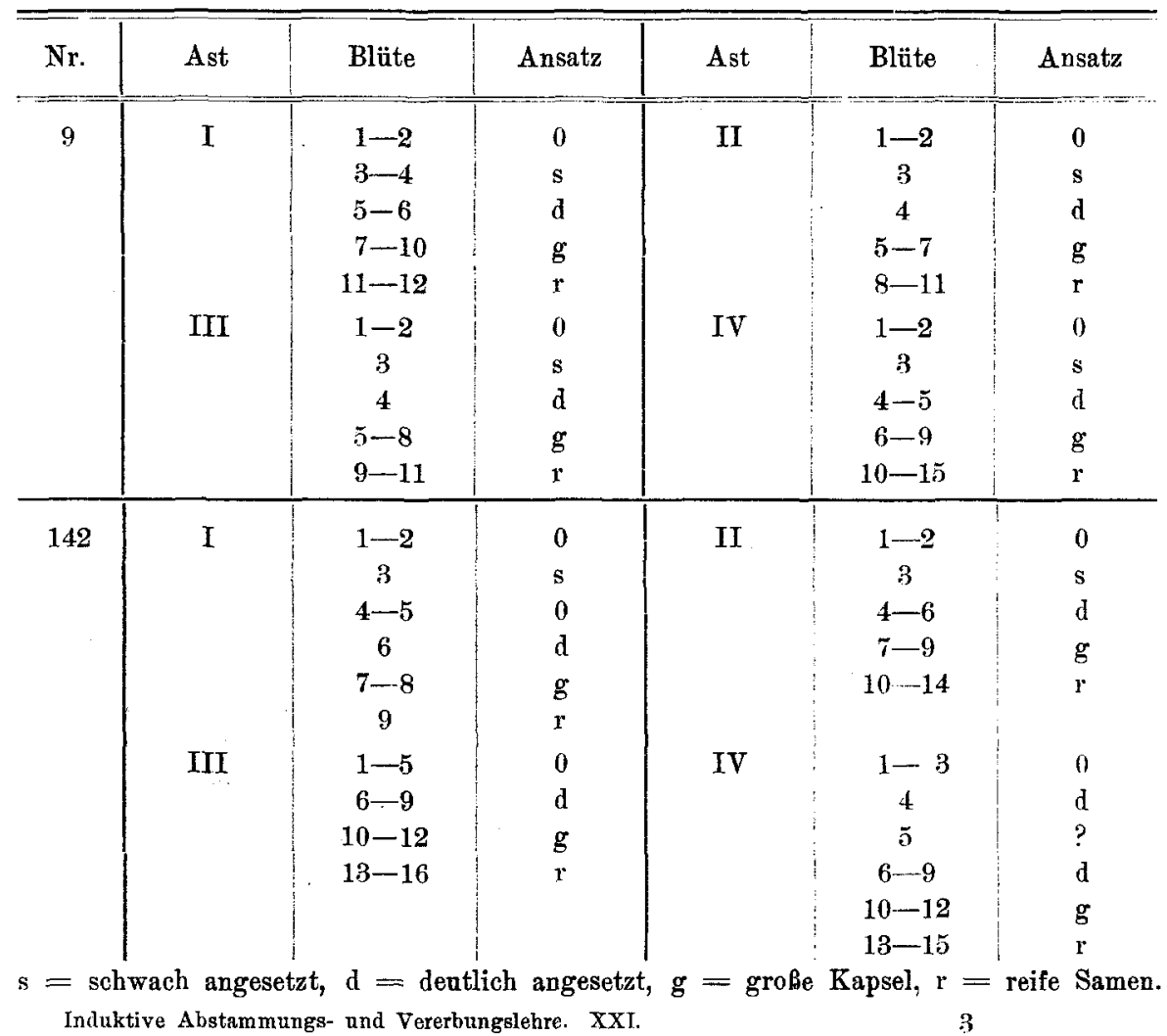


Ganz wie diese als Beispiele angeführten Äste verhielten sich auch die zahlreichen anderen an diesen Pflanzen vorhandenen Äste. Die ersten $2-3$, in einigen Fällen auch $\mathbf{4 - 5}$ abgeblühten Blüten nach der noch geöffneten Blüte vom Tage zeigten wie begreiflich noch keinen oder sehr schwachen Kapselansatz; schon die vierte Blüte zeigte aber in der Regel einen deutlichen Ansatz; je älter die Blüten, umso größer war der Kapselansatz und von der neunten bis zehnten Blüte ab fanden sich in der Regel schon reife Samen. M. a. W.: Ein deutlicher Kapselansatz war in der Regel schon nach 5-7 Tagen, reife Samen aber waren zumeist schon 12-14 Tage nach der Bestänbung zu finden, wenn man berücksichtigt, daß an jedem Ast alle $1-1 / 2$ Tag je eine neue Blüte abblüht.

Ich führe nun zam Vergleich zunächst einmal ein Individuum aus der im Freien isolierten Gruppe A in derselben Weise auf:

Nr. 34 (Gr. A) 14. Juni in meinem Garten isoliert, an 15. Juli untersucht

\begin{tabular}{c|c|c|c|c|c}
\hline Ast & Blüte & Ansatz & Ast & Blüte & Ansatz \\
\hline I & $1-18$ & 0 & VI & $1-20$ & 0 \\
II & $1-2$ & 0 & VII & $1-16$ & 0 \\
& 3 & s & VIII & $1-18$ & 0 \\
& $4-20$ & 0 & IX & $1-18$ & 0 \\
III & $1-6$ & 0 & X & $1-8$ & 0 \\
& 7 & $\mathrm{~s}$ & & 9 & $\mathrm{~s}$ \\
& $8-16$ & 0 & & $10-11$ & 0 \\
IV & $1-16$ & 0 & & $12-13$ & $\mathrm{~s}$ \\
& 16 & $\mathrm{~d}$ & & $14-23$ & 0 \\
& $17-25$ & 0 & XI & $1-18$ & 0 \\
V & $1-22$ & 0 & & usw. &
\end{tabular}

Aus diesem Beispiele geht nun schon hervor, daß die Verhältnisse hier durchaus anders liegen. Fast jeder Ansatz fehlt, nur einige schwache Kapselansätze sind bemerkbar, die aber auch während der langen Zeit der Isolation nicht zu weiterer Entwicklung gekommen sind, sondern auf dem jugendlichen Stadium stehen geblieben sind. Öffnet man diese jungen Kapseln, so findet man vertrocknete Samenanlagen darin.

Ich habe nun aber, um diese Tatsache auf viel breitere Basis zu stellen, alle abgeblühten Blüten sämtlicher gruppenweise im Freien 
untergebrachten und noch in gutem Zustand befindlichen Pflanzen auf ihren Kapselansatz hin studiert und stelle das Ergebnis im folgenden zusammen.

Gruppe A.

\begin{tabular}{|c|c|c|c|c|c|}
\hline Pflanze & Kein Ansatz & $\begin{array}{c}\text { Sehr kleine } \\
\text { Kapseln }\end{array}$ & $\begin{array}{c}\text { Kleine } \\
\text { Kapseln }\end{array}$ & $\begin{array}{l}\text { Größere } \\
\text { Kapseln }\end{array}$ & $\begin{array}{c}\text { Kapseln } \\
\text { gesamt }\end{array}$ \\
\hline 3 & 482 & 1 & 2 & 2 & 5 \\
\hline 69 & 384 & - & 9 & 6 & 15 \\
\hline 60 & 553 & 1 & 3 & 2 & 6 \\
\hline 138 & 174 & - & 4 & 6 & 10 \\
\hline 35 & 140 & 3 & 4 & 1 & 8 \\
\hline 31 & 130 & - & 1 & - & 1 \\
\hline 154 & 63 & - & - & - & 0 \\
\hline 2 & 140 & - & 2 & - & 2 \\
\hline 57 & 772 & 1 & 7 & 5 & 13 \\
\hline 5 & 302 & - & 4 & - & 4 \\
\hline 81 & 344 & - & 4 & - & 4 \\
\hline 165 & 299 & - & 3 & 1 & 4 \\
\hline \multirow[t]{2}{*}{17} & 159 & - & 6 & - & 6 \\
\hline & $3941=98 \%$ & 6 & 49 & 23 & $78=2 \%$ \\
\hline
\end{tabular}

Gruppe B.

\begin{tabular}{r|r|r|r|r|r}
\hline 165 & 179 & - & 3 & - & 3 \\
42 & 497 & 5 & 4 & 2 & 11 \\
18 & 14 & - & 1 & - & 1 \\
67 & 145 & - & - & - & - \\
63 & 25 & - & - & - & - \\
8 & 151 & - & 3 & - & 3 \\
1 & 131 & - & - & - & - \\
95 & 84 & - & 1 & - & 1 \\
153 & 41 & - & - & - & - \\
87 & 18 & - & - & - & - \\
\hline & $1205=98,6 \%$ & 5 & 12 & 2 & $17=1,4 \%$ \\
\end{tabular}


Gruppe C.

\begin{tabular}{|c|c|c|c|c|c|}
\hline Pflanze & Kein Ansatz & $\begin{array}{c}\text { Sehr kleine } \\
\text { Kapseln }\end{array}$ & $\begin{array}{l}\text { Kleine } \\
\text { Kapseln }\end{array}$ & $\begin{array}{l}\text { Größere } \\
\text { Kapseln }\end{array}$ & $\begin{array}{l}\text { Kapseln } \\
\text { gesamt }\end{array}$ \\
\hline 25 & 174 & 1 & 22 & 11 & 34 \\
\hline 130 & 71 & - & 3 & - & 3 \\
\hline 111 & 69 & - & - & - & - \\
\hline 56 & 79 & 1 & 1 & - & 2 \\
\hline 61 & 272 & 2 & 4 & - & 6 \\
\hline 113 & 128 & - & 1 & - & 1 \\
\hline 64 & 136 & - & 2 & 4 & 6 \\
\hline 152 & 131 & - & 1 & 3 & 4 \\
\hline 92 & 16 & - & 2 & 一 & 2 \\
\hline 123 & 33 & - & - & - & - \\
\hline 160 & 70 & - & - & - & - \\
\hline 112 & 15 & - & - & - & - \\
\hline 33 & 93 & - & 4 & 7 & 11 \\
\hline 73 & 72 & - & 1 & 3 & 4 \\
\hline 83 & 89 & - & 3 & 7 & 10 \\
\hline 102 & 174 & - & 4 & 5 & 9 \\
\hline 145 & 119 & - & 5 & 4 & 9 \\
\hline 106 & 61 & - & 3 & - & 3 \\
\hline 119 & 112 & - & 1 & 2 & 3 \\
\hline 91 & 64 & - & - & - & $\cdots-$ \\
\hline \multirow[t]{2}{*}{32} & 152 & - & 6 & 9 & 15 \\
\hline & $\begin{aligned} 2130 & =\mathbf{9 4 , 3} \% \\
\text { ohne } 25 & =\mathbf{9 5 , 9 \%}\end{aligned}$ & 4 & 63 & 55 & $\begin{aligned} 122 & =5,7 \% \\
\text { ohne } 25 & =4,1 \%\end{aligned}$ \\
\hline
\end{tabular}

Gruppe I.

\begin{tabular}{r|r|r|r|r|r}
137 & 172 & - & - & - & - \\
14 & 157 & - & 1 & - & 1 \\
50 & 181 & - & 1 & - & 1 \\
20 & 94 & - & - & - & - \\
147 & 126 & 2 & 3 & 3 & 8 \\
55 & 162 & - & 1 & - & 1 \\
143 & 150 & - & 4 & - & 4 \\
127 & 84 & - & 1 & - & 1 \\
77 & 44 & - & - & - & - \\
70 & 46 & - & - & 3 & 3 \\
$?$ & 145 & 3 & 9 & - & 12 \\
128 & 148 & - & - & - & - \\
\hline & $1509=98 \%$ & 5 & 20 & 6 & $31=2 \%$
\end{tabular}


Aus der vorhergehenden Übersicht läßt sich zunächst erkennen, daß ganz allgemein, wie nach den früher beschriebenen Kreuzungsversuchen unter Isolation, auch im Freien innerhalb ein und derselben Gruppe Sterilität herrschte. Im allgemeinen in sehr geringer Anzahl kam es neben völligem Stehenbleiben des Fruchtknotens auch nach Bestäubung im Freien zu geringer Anregung der Kapselbildung. Die Kapsel blieb aber dann im unfertigen Zustand stehen, im inneren befanden sich keine Samen. Ich habe eine große Anzahl solcher unfertiger Kapseln fixiert, um sie später genauer zu untersuchen. Der Prozentgehalt der unfertigen Kapseln wechselte etwas von Individuum zu Individuum, blieb aber im allgemeinen in bescheidenen Grenzen, durchschnittlich $2-3 \%$. Einesteils wurden häufig überhaupt keine Kapseln gefunden, andererseits fanden sich an einer Pflanze (C 25) nahezu 20\% rudimentäre Kapseln, stets aber ohne entwickelte Samen, eine besondere Bevorzugung der einen oder anderen Gruppe in der Kapselbildung war nicht zu bemerken. In ganz vereinzelten Fällen wurden auch einige ganz kleine Käpselchen mit ein oder zwei gebräunten, vielleicht auch gereiften Samen gefunden. Ich habe solche Samen natürlich eingesammelt und werde sie auf ihr Verhalten näher prüfen, es waren aber höchstens 4-5 solche Samen, so daß der Prozentgehalt unter 0,1 zu liegen kommt. Auf alle Fälle aber könnte die Nachkommenschaft solcher Samen ebenso wie diejenige von Nr. 120 vielleicht für die $\mathrm{Zu}$ kunft weitere Aufschlüsse erbringen. Vorläufig ist auch durch diese gruppenweise Kultur im Freien die Sicherheit erbracht, daB nach Bestäubung zweier selbststeriler Individuen von $V$. syriaca eine $F_{\mathbf{1}}$ entstanden ist, deren Individuen sich in vier Gruppen einteilen lassen, welche je unter sich vollkommen oder fast vollkommen steril sind. $\mathrm{Zu}$ gleich lassen diuse Versuche erkennen, daß die gelëgentlich bei unseren unter Isolation ausgeführten Kreuzbestäubungen aufgetretenen unerwarteten Ansätze zum größten Teile solche auf unfertigem Zustand stehen gebliebene Kapseln gewesen sein dürften.

\section{Selbststerilität.}

Schon bei meinen früheren Untersuchungen mit Veronica syriaca ich habe diese Pflanzen zwecks Bastardierung und Untersuchung der Kronenanomalien seit 1911 in Kultur - habe ich stets absolute Selbststerilität feststellen können: aber auch während meiner in dieser Abhandlung besprochenen Untersuchungen zeigte sich die Pflanze stets selbststeril. 
Ich habe zunächst bei 94 meiner Versuchspflanzen, teilweis wiederholt, Selbstbestäubungen angestellt, stets mit negativem Resultat.

Ich habe weiter 57 Pflanzen wochenlang im Freien nur unter ihren eigenen Gruppenmitgliedern gehalten. Sie haben, wie wir sahen, niemals Samen angesetzt, sind also sicher auch selbststeril gewesen. Da unter diesen 57 Pflanzen 20 waren, welche nicht selbst noch besonders bestäubt worden waren, erhöht sich die Zahl der sicher selbststerilen in meiner $F_{1}$ auf 114 .

Ob die wenigen bei Nr. 120 in Isolation erhaltenen Samen auf irgend welches Versehen zurückzuführen sind, oder wirklich durch Selbstbestäubung erzielt wurden, bleibt einstweilen zweifelhaft. Daß auch aus jahrelang als selbststeril festgestellten Pflanzen gelegentlich selbstfertile auftreten können, wurde ja jüngst von Stout bei Cichorium beobachtet. Für V. syriaca liegt aber noch kein sicherer Anhalt dafür vor. Wir müssen also die von mir untersuchte Rasse von $V$. syriaca vorläufig als durchaus selbststeril anffassen.

\section{Mendelistische Erklärungsversuche.}

Es ist nicht $\mathrm{zu}$ bezweifeln, daß die Selbststerilität, wie ich sie hier bei V. syriaca näher stadiert habe, weitgehende Beziehungen aufweist zu den von Correns bei Cardamine pratensis beobachteten Verhältnissen. Wenngleich es sich bei meinen Untersuchungen um das Studiun der Individuen der $F_{1}$ handelt, während Correns vorzüglich Bestäubungsversuche zwischen $\mathrm{F}_{1}$-Individuen und deren Eltern anstellte, so dürfte eine vorläufige vergleichende Betrachtung in aller Kürze hier doch wohl am Platze sein.

Correns nimmt an, dab die Selbststerilität von Cardamine pratensis auf Hemmungsstoffen beruht, für welche richtige Anlagen vorhanden sein sollen, welche sich nach den Mendelschen Vererbungsgesetzen vererben. Er sagt wörtlich: „Es handelt sich (vielmehr) um Stoffe, die den niedrigsten systematischen Einheiten - wir wollen sie mit Johannsens Linien ${ }^{1}$ ) identifizieren - eigen sind: die Henmungsstoffe sind Linienstoffe ${ }^{1}$ )" oder S. 31: "Wir müssen (vielmehr) in den Hemmungs-

1) Correns hat schon selbst (1916, S. 7, Ann.) darauf hingewiesen, daß Linie eigentlich den lückenlosen Zusammenlang der Individuen dureh Generationen bei ausschließlicher Selbstbefruchtung bedeutet. Er fährt dann weiter fort: „Man kann aber auch die Individuen mit dem gleichen, konstanten. "Genotypus" (Johannsen) d. h. mit 
stoffen Linienstoffe sehen, deren Ausbildung auf der Anwesenheit einer Anlage beruht, die vererbt wird, die sogar wahrscheinlich dem Mendelschen Spaltungsgesetz folgt."

Doch betrachten wir nun zunächst, wie diese von Correns postulierten Anlagen für die Hemmungsstoffe sich nach den Mendelschen Vererbungsgesetzen vererben sollen. Correns (S. 16) geht aus von zwei Elterindividuen. Jedes der Eltern bildet mindestens einen aktiven Hemmungsstoff aus, in unserem Falle das eine Individuum $\mathfrak{B}$ den Stoff $B$, das andere \& den Stoff G. Außerdem ist bei jedem noch mindestens eine Anlage für einen anderen Hemmungsstoff im inaktiven Zustande vorhanden (als nicht entfaltete Anlage); wir wollen den des einen Elters b, den des anderen $\mathrm{g}$ nennen. Die "Erbformeln" wären dann $\mathrm{Bb}$ für das eine und Gg für das andere Elter. Bei der Keimzellbildung tritt nun eine Spaltung ein; das eine Elter bildet zur Hälfte Keimzellen mit der Anlage B, zur Hälfte solche mit der Anlage b, und das andere Elter zur Hälfte Keimzellen mit der Anlage $G$, zur Hälfte solche mit der Anlage g. Bestäubt màn nun diese Eltern wechselseitig miteinander, so sind acht Kombinationen gleich gut und gleich oft möglich:

\begin{tabular}{|c|c|c|c|c|c|}
\hline $\begin{array}{c}\text { Kom- } \\
\text { bination }\end{array}$ & $\begin{array}{c}\text { Eltern } \mathfrak{B}+\underset{+}{ }+\mathbb{S} \sigma^{\nearrow} \\
\text { Keimzellen }\end{array}$ & $\begin{array}{l}\text { Resultat } \\
\text { Kinder }\end{array}$ & $\begin{array}{c}\text { Kom- } \\
\text { bination }\end{array}$ & $\begin{array}{c}\text { Eitern } \mathscr{G}+0+\mathfrak{B} \sigma^{7} \\
\text { Keimzellen }\end{array}$ & $\begin{array}{l}\text { Resultat } \\
\text { Kinder }\end{array}$ \\
\hline 1 & $B+G$ & $\mathrm{BG}$ & $\tilde{\mathbf{s}}$ & $G+B$ & $G B$ \\
\hline 2 & $\mathbf{B}+\mathbf{g}$ & $\mathrm{Bg}$ & 6 & $G+b$ & $\mathrm{~Gb}$ \\
\hline 3 & $b+G$ & bG & 7 & $g+B$ & $g B$ \\
\hline 4 & $b+g$ & bg & 8 & $g+b$ & $g b$ \\
\hline
\end{tabular}

Daß $B$ mit $b$ und $G$ mit $g$ wieder zusammen kommen, ist durch die Selbststerilität verhindert, die keine Vereinigung der Keimzellen

völlig gleichen erblichen konstanten Anlagen unter diesem Namen zusammenfassen weil sie auf diesem Wege nachgewiesen worden sind -, wenn man nicht lieber mit E. Lehmann (Art, reine Linie, isogene Einheit, Biol. Centralbl. 34, S. 285, 1914) isogene Einheit sagen will.“ Ich möchte an dieser Stelle auf die Begriffe reine Linie und isogene Einheit nicht wieder zurückkommen, glaube aber an der von Correns genannten Stelle und später zweifelsfrei dargelegt zu haben, dab einte Verwendung der Bezeichnung Reine Linie in dem von Correns hier gewünschten Sinne nieht angängig ist und daß reine Linie und isogene Einheit prinzipiell verschiedene Dinge sind. Infolgedessen erscheint mir auch die Bezeichnung Linienstoffe, welche bei Selbststerilen unmöglich sind, nicht übermäßig glïcklich zn sein. 
desselben Individuums zuläßt, gleichgültig, was für eine Anlage sie übertragen.

Es ergeben sich also vier gleich große Individualklassen, welche von Correns tatsächlich beobachtet wurden. „Das Verhalten den beiden Eltern gegenüber erklärt sich“, wie Correns weiter fortfährt, "auch ohne weiteres, wenn man im Sinne behält, daB B und G die Anwesenheit der Hemmungsstoffe der Eltern bedeutet, $b$ und $g$ deren Fehlen. B verbunden mit B muß also z. B. ohne Ergebnis bleiben, $b$ mit $B$ ansetzen.

\begin{tabular}{|c|c|c|c|c|}
\hline Kinderklasse & $\begin{array}{c}\text { Bestäubt mit dem } \\
\text { Elter }\end{array}$ & Resultat & $\begin{array}{c}\text { Bestäubt mit dem } \\
\text { Elter }\end{array}$ & Resultat \\
\hline $\begin{array}{l}\text { BG } \\
\text { Bg } \\
\mathrm{bG} \\
\mathrm{bg}\end{array}$ & B & $\begin{array}{l}- \\
+ \\
+\end{array}$ & $G$ & $\frac{-}{+} \frac{-}{+}$ \\
\hline
\end{tabular}

Klasse BG ist also mit beiden Eltern steril, Klasse bg mit beiden fertil, Klasse $\mathrm{Bg}$ nur mit G, Klasse bG nur mit B fruchtbar."

Gegen diese Annahmen von Correns lassen sich einige Einwände erheben, welche z. T. schon vorgebracht wurden und auf die ich jetzt kurz eingehen möchte.

1. Zunächst hat Correns selbst schon das Folgende hervorgehoben, was mit seiner Theorie noch nicht ins Einvernehmen zu bringen ist: „Um zu erklären, daß die Individuen der Klasse BG mit dem Pollen beider Eltern nicht ansetzen, müssen wir annehmen, daß sie die Hemmungsstoffe dieser beiden Eltern auch wirklich ausbilden. B darf weder über $G$ dominieren, noch ihm gegenüber rezessiv sein. Umgekehrt mußten wir aber annehmen, daß von den Hemmungsstoffen, die sowohl das eine als das andere Elter $\left(\mathrm{P}_{1}\right)$ von seinen beiden Eltern $\mathrm{P}_{2}$ (den Großeltern BG, Bg usw.) überkommen haben, der eine entfaltet, der andere inaktiv geblieben ist. Sonst hätten wir das Ansetzen von bg mit beiden Eltern nicht erklären können". Hier müssen weitere Untersuchungen einsetzen.

2. Compton, East und Sirks haben darauf hingewiesen, daß ohne Hilfsannahmen aus der Mendelschen Regel nicht zu verstehen ist, dab die Pflanzen bg, welche doch keine Hemmungsstoffe besitzen, nicht selbstfertil sind. Sirks hat auch den Fall erörtert, welcher ja 
von Correns selbst schon mit herangezogen wird, daß mehr als zwei Hemmungsfaktoren vorhanden sind, kam aber dabei zu nicht zu überwindenden Schwierigkeiten.

3. Auf eine weitere Schwierigkeit, die meiner Meinung nach aber nicht in vollem Umfange zu Recht zu bestehen braucht, hat dann Sirks hingewiesen. Er sagt (S.259): „A l'occasion de la synthèse de la génération Correns admet que les deux parents font deux sortes de cellules sexuelles, savoir une plante $B$ et $b$, l'autre $G$ et $g$ et à la page suivante, où le croisement des enfants des types $B G, B g$, $b G$ et bg avec les deux parents est représenté dans le tableau schématique 7 , il admet les deux parents „als ganzes“, c. à d. qu'il fait comme si l'un re formait que le pollen B, l'autre seulement que du pollen G:" (vergl. die letzte Tabelle).

"Les enfants obtenus ne furent pas pollinisés par les parents, mais avec du pollen des parents et ce pollen, selon Correns, était composé de grains $B$ et de grains $b$ (respectivement $G$ et g). Par couséquent les grains b parmi tous ces grains de pollen devraient être en état de féconder les plantes BG et Bg. Et voilà Correns qui fait s'il n'y avait plus de difficultés à vaincre."

Nun wäre allerdings, wenn man das Pollenkorn rein als Gamet auffaßte, gegen die Beweisführung von Sirks nichts einzuwenden. Andererseits scheint die Tabelle von Correns dazu zu verführen, anzunehmen, anch Correns sei so vorgegangen. Denn vorher benennt er immer die Anlage im Gameten mit lateinischen Buchstaben, die ganze Pflanze aber mit deutschen Buchstaben. Hier aber führt er den lateinischen Buchstaben für das ganze Pollenkorn ein, das Pollenkorn aber faßt er doch offenbar als Teil der Elternpflanze nach seiner Anm. auf S. 19. Und es ist auch wohl zweifellos, daß der. Einwand von Sirks nicht stichhaltig zu sein braucht. Denn das Pollenkorn ist ja eben nicht nur Gamet. Wir können vielmehr vielleicht annehmen, daß die Hemmungsstoffe von der Elternpflanze sich trotz Reduktionsteilung noch im Plasma oder in der Wandung des Pollenkornes befinden, etwa wie der grünlichblaue Farbstoff des roten Elters sich noch in der Intine aller Pollenkörner des Bastardes Epilobium angustifolium rot $\times$ weiß befindet (vergl. Correns, Bot.Ztg. 1900, S.23). Vielleicht könnte man auch daran denken, daß von Tapetenzellen bezw. Periplasmodium die Hemmungsstoffe in das Pollenkorn übergehen. Daun würde natürlich auch beim Zusammentreffen des auf der Pflanze Bb entstandenen Pollenkornes, in welchem der Hemmungsstoff $\mathrm{B}$ genotypisch, also im Gameten nicht mehr vorhanden ist, mit der Narbe einer Pflanze BG die Vereinigung durch den im Plasma oder in 
der Wandung dennoch anwesenden Hemmungsstoff unmöglich werden können. Das Nichtzustandekommen von Selbstfertilen der Klasse bg wird aber dadurch nicht berührt.

4. Ein weiterer Punkt scheint mir wenigstens zu bedenken zu sein. Bei der Auswahl der Elternpflanzen zu der Corrensschen Bastardierung hat nur der Zufall mitgespielt. Correns benutzte zwei beliebige Pflanzen aus den Rasenflächen des Münsterer botanischen Gartens. In diesen Rasenflächen müssen nach Correns' Annahme zum mindesten Pflanzen mit folgender "Linienstoff"konstitution wachsen: $\mathrm{Bb}$, $\mathrm{Gg}, \mathrm{BG}, \mathrm{Bg}, \mathrm{bG}, \mathrm{bg}$. Correns hat zufällig zwei Pflanzen mit der korrespondierenden Konstitution gewählt. Es wären natürlich auch andere Möglichkeiten gewesen, welche $z$. T. durchaus nicht zu der gleichmäßigen Gruppenbildung in $F_{1}$ hätten führen müssen.

5. Nun ist ja aber etwas weiteres außer jedem Zweifel. Um zwei Hemmungsstoffe allein kann es sich bei Cardamine pratensis durchaus nicht handeln. Es müssen sicher viel mehr Hemmungsstoffe vorliegen, wenn man die Ergebnisse von Correns verständlich machen will. Und Correns selbst denkt ja auch an eine erheblich größere Zahl. Um das zu verstehen, müssen wir uñs einmal daran erinnern, daß Correns seine beiden Elternpflanzen sowohl als die in vier Gruppen zerfallenden Kinderpflanzen mit zwei sicher nicht verwandten Pflanzen, die eine vom Züricher See, die andere aus Schwaben gekreuzt hat. Alle Kombinationen mit diesen Pflanzen waren fruchtbar. Von den Eltern und den 60 Kinderpflanzen von Correns hatte also keine denselben Hemmungsstoff gebildet, wie die Pflanzen vom Züricher See und aus Schwaben. Man wird nun nieht annehmen können, daß gerade die Pflanzeu des Münsterer botanischen Garteus und diejenigen vom Züricher See bezw. ans Schwaben quasi komplementäre Pflanzen gewesen seien. Man wird vielmehr die Ansicht vertreten müssen, daß, wenn Correns beispielsweise Cardamine aus dem Wiener Prater oder aus der Gegend von Königsberg sich hätte zusenden lassen, seine Pflanzen auch mit diesen jedenfalls alle fertil, ja vielleicht die Wiener, Züricher, Königsberger und Nürtinger untereinander auch wieder fertil gefunden haben würde. Man würde auf diese Weise sicher schon zu einer recht großen Anzahl von "Linienstoffen" kommen. Die Zahl vergrößert sich aber noch erheblich; denu nach Correns soll auch die Klasse bg hinsichtlich ihrer Hemmungsstoffe nicht einheitlich sein. Auf S. 29 heißt es: "Zweifellos sind also die Klassen BG, bG und vor allem bg hinsichtlich ihrer Hemmungsstoffe nicht einheitlich und es liegen ihrem Verhalten noch besondere Gesetzmäßigkeiten zu Grunde." 
Wenn aber bg nicht einheitlich sein soll, dem doch beide Hemmungsstoffe, jedenfalls im entfalteten Zustand fehlen, so müssen entweder noch andere Hemmungsstoffe vorliegen, oder wir müssen andere Hilfsannahmen machen. Ebenso wie wir Individualstoffe in unendlicher Zahl annehmen können und erklärlich finden, können wir vielleicht heute mit noch größerem Recht auch das Auftreten von zahlreichen solchen Linienstoffen - immerhin begrenzter Anzahl - als Hypothese annehmen (vergl. Correns 1916, S. 18, Sep. A). Wir können aber dann nicht mit so einfachen mendelistischen Ansätzen vorgehen wie Correns das tut. Wollen wir hier weiter kommen, so werden wir durch Erziehung immer genotypisch einheitlicherer Fflanzen das Ziel zu erreichen suchen müssen. Das hat ja schon Correns vorgeschwebt. Vielleicht aber waren die Cardaminepflanzen, welche er als Ausgangsmaterial benutzte, noch zu verschieden.

Versuchen wir nun aber einmal für meine l. syriaca-Kreuzungen das Schema von Correns zugrunde zu legen. Wir hätten dann wie Correns die Kinder

$$
\mathrm{BG}, \mathrm{Bg}, \mathrm{bG}, \mathrm{bg} \text {. }
$$

Es wäre anch hiẹr zunächst recht merkwürdig, warum ich keine selbstfertilen bg gefunden hätte. Schon unter der Annahme von vier Hemmungsfaktoren wäre allerdings das Auftreten von Selbstfertilen bei meinen Zahlen nicht mehr unbedingt nötig gewesen. Bleiben wir aber bei dem Schema von Correns stehen, dann hätte ich doch sicher auch bg-Pflanzen auffinden müssen, welche mit allen anderen Pflanzen, etwa wie Linaria Pfl. B (Correns 1916, S. 25) fertil waren. Das habe ich aber niemals gefunden. Schon diese eine Tatsache macht den Ansatz von Correns für uns unmöglich, wenigstens dann, wenn man ihn rein mendelistisch, ohne Hilfsannahmen auffassen will.

Kommen wir mit dieser Kombination von Correns nicht aus, so wäre es die Aufgabe, mit Hilfe anderer Ausgangskombinationen und Hilfsannahmen zum Ziele zu gelangen, z. B. mit Hilfe zahlreicherer Faktoren, Ausschalten von Gametenkombinationen, Koppelungen usw. Wir wollen das vorläufig noch unterlassen und einige andere Überlegungen anstellen.

Zunächst, wenn wirklich die Kombinatorik von verschiedenen Hemmungsstoffen hier die Selbststerilität zu erklären imstande ist, so müssen bestimmtgerichtete Kreuzungsversuche darauf hinweisen. Denken wir uns in den Klassen A, B, C, D, welche ich bei V. syriaca aufgestellt habe, je einen oder auch mehrere Hemmungsgene, welche es 
eben nach sich ziehen, daß innerhalb dieser Gruppen dauernde Sterilität besteht. Nehmen wir diese Hemmungsgene, wie wir ja müssen, in den verschiedenen Gruppen verschieden an, so müssen sich doch zweifellos bei weiteren Kreuzungen in den Zahlenverhältnissen Verschiedenheiten ergeben. Bringen wir z. B. die Kreuzung Gruppe A mal Gruppe B zustande und bestäuben die $F_{1}$-Individuen dieser Gruppe untereinander, so müßte sich unter allen Umständen viel hänfiger Selbststerilität finden, als wenn man die $\mathrm{F}_{1}$-Individuen genannter Gruppen etwa mit $\mathrm{F}_{1}$-Individuen der Gruppe C mal D miteinander verbindet. Ich habe entsprechende Kreuzungen vorbereitet und werde diese Frage weiter verfolgen.

Ich möchte nun aber die Frage der Mendelschen Vererbung der Selbststerilität noch von einer anderen Seite betrachten. Zunächst einmal wollen wir uns dazu der Untersuchungen von Compton mit Reseda odorata erinnern. Compton findet wie schon Darwin selbststerile und selbstfertile Pflanzen von Reseda odorata. Selbststerile unter sich gekreuzt geben nur wieder selbststerile Nachkommenschaft, Selbstfertile unter sich gekreuzt, geben nur Selbstfertile. Kreuzt man beide untereinander, so erhält man nur Selbstfertile. Bei Selbstbestäubung ergeben Selbstfertile teilweise eine Nachkommenschaft von $3: 1$ selbstfertil zu selbststeril; weın gekreuzt mit Selbststerilen, ungefähr die Hälfte Selbststerile und Selbstfertile. Compton schließt darans auf Erblichkeit von Selbststerilität und Selbstfertilität und Spaltung nach einfachem Mendelschen Schema. Correns erwähnt diese Ergebnisse von Compton indem er sagt (1916, S. 24): „Compton hat gezeigt, daß bei der Bastardierung selbststeriler und selbstfertiler Individuen der Gartenréseda die Selbststerilität als solche wahrscheinlich als ein einfaches mendelndes Merkmal vererbt wird. Das Zustandekommen der Selbststerilität hat er nicht untersucht." Wenn wir mit Compton und Correns dies aber als gegeben betrachten, so haben wir zwei erbliche Sippen, eine rezessive selbststerile und eine dominante selbstfertile. Sowie wir aber in diesem Falle die Selbststerilität als einfaches rezessives Merkmal anerkennen, sofort wird es mit der Erklärung der Selbststerilität durch Kombination von Linienstoffen zweifelhaft. Wenn wirklich alle Individuen dieser rezessiven selbststerilen Sippe untereinander fertil sind, dann stehen wir wieder vor der Frage, woher kommt die Selbststerilität in jedem einzelnen Individuum; dann müssen wir wieder individuelle Differenzen annehmen,. sei es nun, wir wollten wieder auf Individualstoffe zurückgreifen oder aber mit Sirks vielleicht osmotische 
Verhältnisse in Griffelkanal verantwortlich machen. Sowie wir aber die selbststerile Sippe im Falle Reseda als aus Kombination durch verschiedene "Linienstoffe" aufgebaut annehmen wollen, sofort hört die Annahme auf, es könne sich bei Reseda um ein einfaches rezessives Merkmal bei der Selbststerilität handeln.

Ganz entsprechend dürfte die Sachlage wohl bei manchen Baurschen Antirrhinumarten sein, wo ja auch Selbststerilität einfach rezessiv sein soll.

Auch hier allerdings ließe sich ein Einwand machen. Wenn die selbststerilen Antirrhinum- und Resedaarten nicht völlig selbststeril wären, sondern nur bei Selbstbefruchtung stark gehemmt, so daß sich verein zelte Selbstbestäubungen ausführen ließen, und wenn ganz entsprechend bei Kreuzung der selbststerilen Individuen untereinander sich auch nur vereinzelte Kreuzungen ausführen ließen, so würde sich ein der rezessiven Gruppe eigener Hemmungsfaktor annehmen lassen. Man könnte da an die Verhältnisse bei der heterostylen Primula denken,. wo ja auch langgriffelig $\times$ langgriffelig viel weniger günstige Resultate gibt, als bei Kreuzung mit kurzgriffelig, wo aber langgriffelig eben doeh bei Selbstbestäubung wie bei Kreuzbestäubung (langgriffelig $\times$ langgriffelig) Nachkommen ergibt. Dabei erweisen sich die langgriffeligen ja als rezessiv. Es ist also in langgriffelig ein rezessiver Hemmungsfaktor, welcher nur nicht völlig zur Sterilität führt, sondern nur gradweis. Wie diese Verbältnisse bei Reseda und Antirrhinum allerdings liegen, kann ich z. Z. noch nicht übersehen, wenn diese Fragen auch sicher leicht durch Versuche klärbar sein werden. Indessen scheint der Einwand kaum in allen Fällen zutreffend zu sein. Denn East fand bei Nicotiana bei vollkommener Selbststerilität eine allgemeine, vollkommene Kreuzungsfertilität. Weitere Versuche werden hier klärend eingreifen müssen.

Nach all unseren Überlegungen stehen mendelistischer Dentung der Selbststerilität z. Z. noch erhebliche Schwierigkeiten gegenüber. Ob dieselben sich werden überwinden lassen, wird die Zukunft zeigen.

Man hat unter dem Eindruck dieser Schwierigkeiten neuerdings voll verschiedenen Seiten andere Erklärungsversuche für die Selbststerilität beigebracht. East greift wieder auf die Individualstoffe $J_{0}$ sts zurück, Sirks und Stout modifizieren diese Erklärungsversuche. Ehe ich für meinen Fall der Veronica syrias.a zu all diesen Gedankengängen Stellung nehme, beabsichtige ich noch von verschiedenen Seiten an das Problem der Selbststerilität heranzutreten. Bis dahin möchte ich auf weitere theoretische Erörterungen verzichten. 
Als zweifelsfreie Ergebnisse meiner bisherigen Untersuchungen sind die folgenden mitzuteilen:

\section{E. Ergebnisse.}

1. Veronica syriaca ist eine ausgesprochen selbststerile Pflanzenart. Schon bei jahrelangen Untersuchungen zu anderen Zwecken wurde niemals eine selbstfertile Pflanze beobachtet. In der $\mathrm{F}_{1}$ einer Kreuzung zwischen zwei selbststerilen Individuen wurden 94 Individuen selbstbestäubt; nie wurde im Gefolge der Bestäubung normale Kapsel- und Samenbildung festgestellt. Bei einer Pflanze (120) fanden sich in der Isolation einzelne halbentwickelte Kapseln mit 1-2 gebräunten Samen, die aber bezüglich Reife und Herkunft zweifelhaft sind. Außer diesen 94 wurden noch 20 Individuen, welche innerhalb ihrer Gruppe (s. unter Nr. 2) im Freien aufgestellt waren, stets ohne normale Kapsel und Samenbildung gefunden, so daß im ganzen 114 sicher selbststerile Pflanzen - d. s. alle speziell darauf untersuchten - zur Beobachtang kamen.

2. In der $F_{1}$ meiner Kreuzung konnten vier Gruppen von Individuen nach ihren gegenseitigen Kreuzungserfolgen festgestellt werden. Die Angehörigen jeder Gruppe brachten es bei gegenseitiger Bestäubung innerhalb der Gruppe nie zur Ausbildung entwickelter Kapseln mit reifen Samen. Auch nach wochenlangem Verbleib der voneinander getrennten Gruppen im Freien blieben alle Angehörigen dieser Gruppen ohne normalen Ansatz. Dagegen brachten es alle Angehörigen der verschiedenen Gruppen untereinander stets zu vollkommener Fruchtbarkeit.

3. Sofern sich später eine mendelistische Erklärung für das beschriebene Verhalten ergeben wird, werden zweifellos gewisse Hilfsannahmen eingeführt werden müssen. Einstweilen sind die Ursachen für die beschriebene Gruppenbildung noch nicht $\mathrm{zu}$ durchschauen.

\section{F. Literatur.}

Baur, E. 1911. Einführung in die experimentelle Vererbungslehre. 2. Aufl.

Compton, R. H. 1912. Preliminary note on inheritance of sterility in Reseda odorata. Proc. Cambridge Phil. Soc. XVII.

- 1913. Phenomena and problems of selfsterility. New Phytologist vol. XII, S. 197--206.

Correns, C. 1912. Selbststerilität und Individualstoffe. Festschr. d. Med. Nat. Ges.

z. 84. Versamml. Deutsch. Naturf. u. Ärzte. 
Correns, C. 1916. Individuen und Individualstoffe. Die Naturwissensehaften, 1916. H. 14-16.

East, E. M. 1915. The phenomenon of selfsterility. Amer. Nat. vol. XLIX, S. 77-87.

Jost, L. 1907. Über die Selbststerilität einiger Blüten. Bot. Zeit. vol. LXV, S. 77 bis 117.

Lehmann, E. 1918. Vererbungsversuche mit Veronica syriaca. Roem. et Schult. Ber. d. deutsch. bot. Ges. S. 611-619.

Sirks, M. J. 1917. Stérilité, Auto-inconceptibilité et différenciation sexuelle physiologique. Arch. Néerl. des Sc. exactes et natur. sér. B, t. III, S. 205.

Stont, A. B. 1918. Fertility in Cichorinm Intybus. Self-Compatibility and selfincompatibility among the offspring of self-fertile lines of Descent. Journal of genetics, 7, S. $71-103$.

de Vries. 1906. Gesellige Blumen. Kosmos Bd. III, S. 276. 